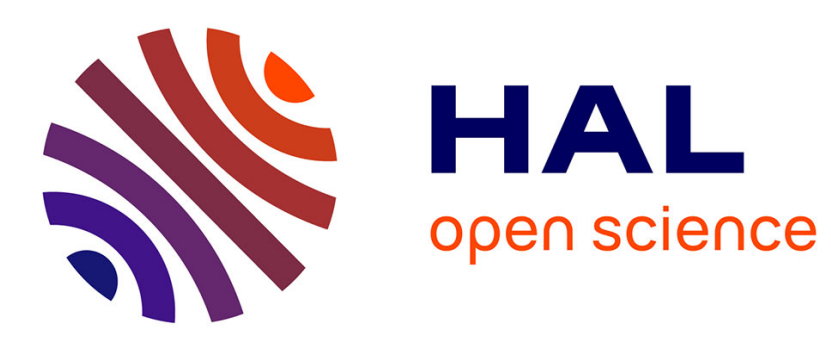

\title{
The Japanese Pioneering Contribution to the Investigation of Modular Structures
}

\author{
Akihiro Umayahara, Massimo Nespolo
}

\section{To cite this version:}

Akihiro Umayahara, Massimo Nespolo. The Japanese Pioneering Contribution to the Investigation of Modular Structures. Crystal Research and Technology, 2019, pp.1900045. 10.1002/crat.201900045 . hal-02270514

\section{HAL Id: hal-02270514 \\ https://hal.univ-lorraine.fr/hal-02270514}

Submitted on 25 Aug 2019

HAL is a multi-disciplinary open access archive for the deposit and dissemination of scientific research documents, whether they are published or not. The documents may come from teaching and research institutions in France or abroad, or from public or private research centers.
L'archive ouverte pluridisciplinaire HAL, est destinée au dépôt et à la diffusion de documents scientifiques de niveau recherche, publiés ou non, émanant des établissements d'enseignement et de recherche français ou étrangers, des laboratoires publics ou privés. 


\section{The Japanese pioneering contribution to investigation of modular structures}

Akihiro Umayahara ${ }^{1,2}$ and Massimo Nespolo ${ }^{1, *}$

${ }^{1}$ Université de Lorraine. CNRS, CRM2, Nancy, France. ${ }^{2}$ Radboud University Nijmegen, Faculty of 4 Science, Mathematics and Computing Science, Institute for Mathematics, Astrophysics and Particle 5 Physics. Postbus 9010, 6500 GL Nijmegen, The Netherlands. 6 Received 26/03/2019 Revised 19/06/2019 Accepted 22/06/2019 Published online 04/08/2019 7

$\begin{array}{ll}\text { Abstract } & 8\end{array}$

Monoarchetypal modular crystal structures are built by regularly juxtaposing modules obtained from the same 9 archetype. At the interface the coordination environment may altered, leading to a chemical modulation that 10 accompanies the structural variability. When this does not occur the result is a series of polytypes, whose building 11 modules are not limited to layers, although the latter represent the most common examples. The symmetry theory 12 of polytypes was developed by the Order-Disorder (OD) school, which however considered only layers as 13 building modules, and only those polytypes in which pairs of layers are geometrically equivalent. Well before the 14 OD school, Ito in Japan recognized the need of a wider algebraic category, that he called "twinned space groups", 15 in which he considered only digonal operations. His approach was later expanded by Sadanaga, who recognized 16 that Ito's "twinned space groups" are space groupoids. In this article the contribution of the Japanese school to the 17 field is traced back, and it is shown that the fundamental concepts later developed in a more systematic way, were 18 already present, in a nutshell, in the works of Ito and Sadanaga; finally, a slightly revised classification of 19 monoarchetypal modular structures is proposed which better reflects the original contribution by the Japanese 20 $\begin{array}{ll}\text { school. } & 21\end{array}$

\section{Introduction}

A crystal structure can be decomposed into elementary building blocks of variable size. In case of non-molecular structures, the smallest and universally known building block is the coordination polyhedron. Bigger and more complex building blocks occur in modular structures, which are built by juxtaposing one or more types of modules. The modules are three-dimensional but less than triperiodic components that can ideally be described as cuts from a structurally and chemically homogeneous parent structure: the archetype, which does not necessarily correspond to a real

* Corresponding author: email massimo.nespolo@univ-lorraine.fr Phone +33-372-745646 Fax +33-372-745218 
structure, or is not necessarily defined in a unique way, although the module is. For example, in the

case of structures based on stacking of layers of equal spheres, the archetype is a structure with 30 periodicity of one layer and whose stacking mode is AA; clearly, this is a structure with less than maximal compactness, which is however realized in a number of derivative structures in which the trigonal prismatic cavities between two layers are partially occupied. If the requirement of maximal compactness has instead to be fulfilled, one can take either the $2 H(h c p)$ structure or the $3 C(c c p)$ 34 structure as archetype: the module is then obtained as a cut at one-half or one-third across the unit 35 cell.

The global symmetry of the modular structure is described by an ordinary space group, whereas the 37 building modules possess only a subperiodic group $G_{m}^{n}$, where $n$ is the number of dimensions of the 38 space and $m$ the number of directions along which the module is periodic $(m<n)$. We are interested 39 in three-dimensional structures; the subperiodic group of the modules can therefore be $G_{0}^{3}$ (point 40 groups, for 0-periodic modules: bricks or blocks), $G_{1}^{3}$ (rod groups, for 1-periodic modules: rods or chains), $G_{2}^{3}$ (layer groups, for 2-periodic modules: layers or sheets).

The modules can be obtained from chemically different archetypes: the resulting structures are 43 known as polyarchetypal structures (diarchetypal being the most frequent case) and are evidently 44 also heterochemical (different composition) with respect to each of the archetypes. Polyarchetypal 45 modular structures correspond to polysomatic series, as defined by Thompson [1]. When the 46 modules are obtained from the same archetype, they are known as monoarchetypal structures. The 47 resulting structure may or may not have the same chemical composition as the archetype; in 48 particular, modifications of the coordination at the interface between two module can alter the chemical composition of the modular structure. In this article we specifically address 50 monoarchetypal structures and present a revised classification scheme with respect to that in [2]. 
Monoarchetypal modular structures are known as cell-twins [3], a term issued from the similarity

with the operations mapping individuals (domains) in twins. The generation of a series of structures

from the juxtaposition of modules is obtained by varying the relative orientation and/or position of

adjacent modules. The monarchetypal nature of the modular structure leaves open a number of

- the juxtaposition may substantially alter the coordination polyhedra at the interface between neighbour modules, resulting in the occurrence of what has been called a "chemical stress" [4];

- cell-twins built by modules of the same size and without chemical stress are polytypes;

- cell-twins with chemical stress accompanied or not by a chemical change have been called heterochemical and isochemical chemical twins respectively [5].

Cell-twinning has been identified as structure-building mechanism in which modules taken from one and the same archetype are juxtaposed in such a way that at the interface atomic sites for both modules coalesce or new atomic sites are created, and this allows for a chemical change which becomes more important the thinner the modules are. This mechanism has been called 66 tropochemical cell-twinning [3] and explains the occurrence of morphotropism [6] in modular 67 structures. A special case corresponds to modules obtained as cuts of different width from the same archetype, as in the case of the lillianite homologous series. In this series, the archetype is the galena $(\mathrm{PbS})$ structure, and the modules are obtained from cuts corresponding to planes of the (311) 70 family. Juxtaposing modules with the same width and filling by Bi the coordination sites at the 71 interface between modules, one gets different structures like lillianite, heyrovskite and galeno- 72 bismuthite. Instead, when the modules have different width, one obtained the components of the so- 73 called "phase V", which spans a region from 66.7 to $73.5 \mathrm{~mol} \% \mathrm{Bi}_{2} \mathrm{~S}_{3}$. These cell-twins have been 74 called contracted twins [3]; they can be considered as an intermediate between monoarchetypal and 
polyarchetypal modular structures because the building modules are different although obtained 76 from the same archetype.

For our analysis we need to briefly remind the reader of the matrix representation of isometries 78 (distance-preserving transformations). Two points in space with coordinates $\mid x, y, z)$ and $\left.\mid x^{\prime}, y^{\prime}, z^{\prime}\right)$ are 79 related by an operation that includes a rotation or rotoinversion component (the linear part) and a translational component. This operation can be represented as a matrix-column pair $(\mathbf{W}, \mathbf{w})$ :

$$
\left.\mathbf{W} \mid x, y, z)+\mathbf{w}=\mid x^{\prime}, y^{\prime}, z^{\prime}\right)
$$

where $\mathbf{W}$ is a $3 \times 3$ unimodular matrix representing the linear part of the operation and $\mathbf{w}$ is a $3 \times 1$ 83 matrix (column matrix) representing the translational part. In the following, we deal with special cases of isometries, namely symmetry operations compatible with the existence of a periodic lattice, i.e. crystallographic symmetry operations.

A point-group operation consists of the linear part $\mathbf{W}$ only; a space-group operation includes also a 87 translational part $\mathbf{w}$, possibly zero. The linear part $\mathbf{W}$ corresponds to an operation of order $n=1,2$, 3, 4 or 6 , which means that $\mathbf{W}^{\mathrm{n}}=\mathbf{I}$, where $\mathbf{I}$ is the identity matrix. Accordingly, $(\mathbf{W}, \mathbf{w})^{n}=(\mathbf{I}, \mathbf{t})$, 89 where $\mathbf{t}$ is a full lattice translations. The matrix-column pair can be synthetically represented by the 90 Seitz notation $\{\boldsymbol{R} \mid \boldsymbol{v}\}$, where $\boldsymbol{R}$ is the Hermann-Mauguin symbol of the linear part and $\boldsymbol{v}$ is the 91 translation part [7]. We will use this notation in the analysis of some examples.

In a twin, the individuals are related by an isometry that does not contain any translational 93 component: it is a crystallographic point-group operation that maps the orientation of the 94 individuals (see, e.g., [8]). In a cell-twin, the modules are related by isometries that do contain 95 translational components: they map the orientation and the position of the modules. If the linear 96 part $\mathbf{W}$ corresponds to an operation of order $n$, then:

$$
(\mathbf{W}, \mathbf{w})^{p}=(\mathbf{I}, \tau), \tau=\mathbf{t} / q, p, q \text { integers }
$$

where $\mathbf{t}$ is a lattice vector of the cell-twin. As we are going to show, the classification of modular 99 structures introduced by Sadanaga [9] actually depends on whether $q=1$ or $q>1$. 
As stated above, isochemical monoarchetypal modular structures without chemical stress are polytypes. According to the official definition [10], polytypes are obtained by "stacking layers of (nearly) identical structure and composition" so that the resulting triperiodic structures "differ only in their stacking sequence". The building modules are clearly requested to be layers, although "a more general definition of polytypism that includes 'rod' and 'block' polytypes may become necessary in the future". Based on this explicit statement, in the following we identify polytypes with isochemical monoarchetypal modular structures built by only one kind of modules, independently on whether these modules are 2-, 1- or 0-periodic.

The symmetry theory of polytypes built by diperiodic modules (layers or sheets) has been presented in various publications; in particular, an extensive treatment has been introduced for layer structures by the so-called OD (Order-Disorder) theory [11]. An OD structure is a structure in which layers are stacked one above the other in a regular way so that pairs of layers are geometrically equivalent; the stacking can give rise to periodic or non-periodicstructures. Therefore, not all polytypes are OD structures: polytypes in which layer pairs are not all equivalent do not satisfy the definition of an OD structure ([12]; see also a discussion in [13]). (Figure 1). Although the official definition [10] does not explicitly mention non-periodic structures, the term "disordered polytypes" does appear in the reports, so that one can consider that all OD structures are polytypes. 


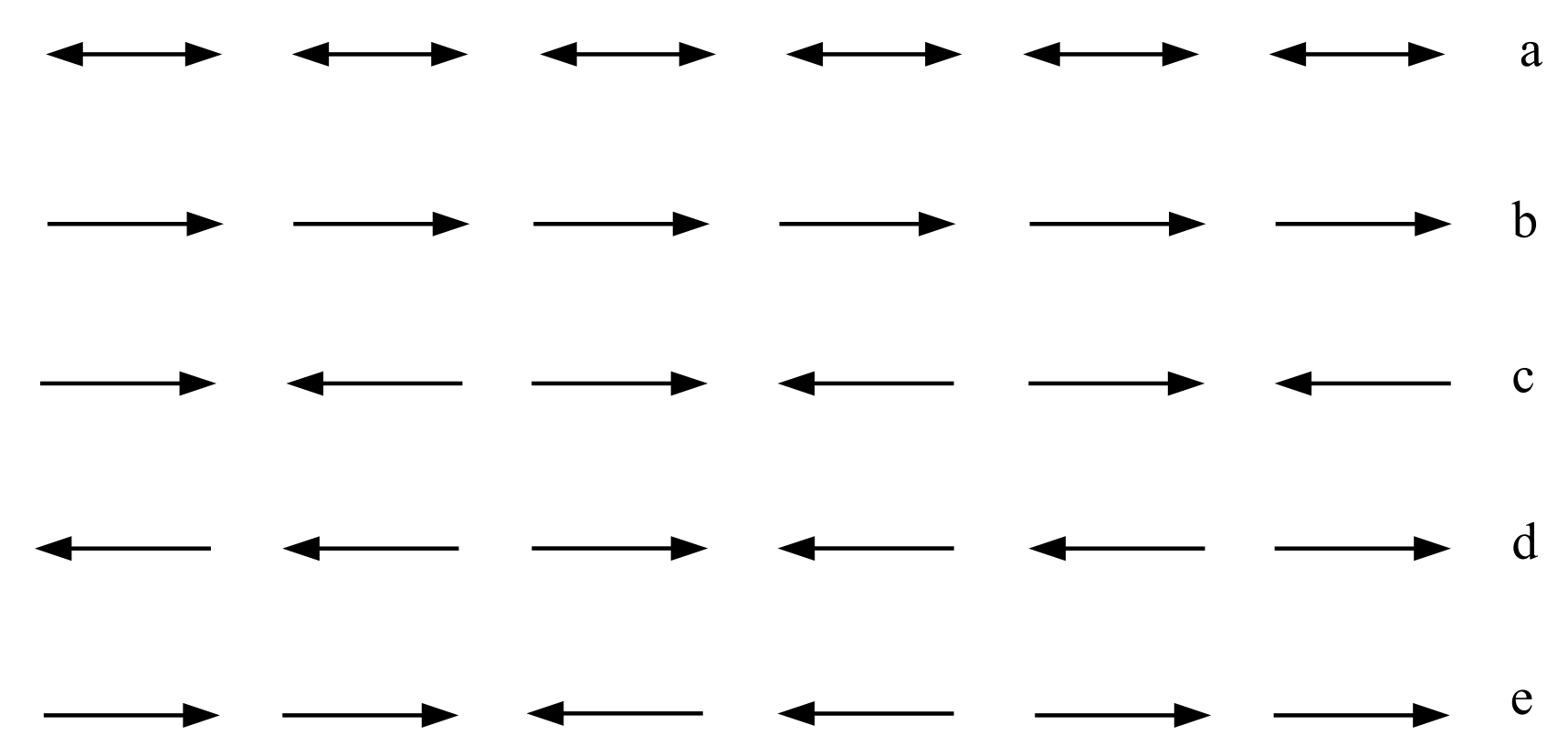

Figure 1 Schematic representation of monoarchetypal modular structures built by the stacking of diperiodic modules (layers). Double and simple arrows represent apolar and polar layers respectively. Polytypes a, b and c are OD structures (classified as type I, II and III respectively), because the layer pairs are geometrically equivalent (the interlayer region has an arrow head or an arrow tail on each side). Polytypes $d$ and e are not, because the layer pairs are not all equivalent due to the the presence of interlayer regions with an arrow head on one side and an arrow tail on the opposite side (modified after [12]).

The mapping of each layer onto itself and onto different layers is realized by isometries that, in general, do not act on the whole crystal space, but only on a subspace of it. These are called, respectively, local and partial operations [9]. In the OD theory, they are both called "partial" operations, because algebraically they are both partial functions, but divided into $\lambda$-operation and $\sigma$ operations, respectively [11], where the Greek letter $\lambda$ is reminiscent of "layer"; further, operations are divided into $\tau$ and $\rho$, depending on whether they keep the orientation of the layer with respect to the stacking direction or invert it. Local and partial operations give rise to an algebraic structure more general than a group, which is known as a groupoid in the sense of Brandt [14] (see Appendix) ${ }^{1}$. Knowing the structure of the layer (and thus its local, or $\lambda$, operations) and the possible stacking operations (i.e. the possible partial, or $\sigma$, operations) one can get a fictitious structure, known as the family structure, obtained by applying to the layer all the possible partial operations so

1 Brandt's original paper is often incorrectly quoted as 1926, whereas it was published one year later. 
that they are "prolonged" to global operation of the family structure, as explained below. These operations are the generators - although not, in general, a minimal set of generators, of the symmetry group of the family structure, which is atomically overpopulated and contains unrealistic bond distances, but can be seen as the common prototype from which all the possible structures are obtained by selecting some of the possible partial operations.

Well before the development of the OD theory, Ito [15] addressed the problem of isochemical monoarchetypal modular structures, starting from the case of pyroxenes, where both monoclinic and orthorhombic polymorphs can be described as obtained by the stacking of (somewhat idealized) layers (a modern analysis has been presented in [16]). Unfortunately, the bulk of the theory was published in an article in Japanese [17] and remains still today essentially unknown outside Japan. Later, Ito [18] extended this approach to a large number of isochemical monoarchetypal modular structures occurring in minerals; the theoretical description was however limited to a few pages in the introduction, used terms that did not follow in the literature, and remains somehow imprecise. Sadanaga, who was a student of Ito, influenced by the approach of the OD school, tried to extend Ito's approach in a more general and formal way. He called the archetype fundamental structure, the module substructure and the structures obtained by stacking the modules complex structures; unfortunately, he introduced some contradictory definitions which resulted in a somewhat confused scheme which, instead of bringing forward Ito's innovative ideas eventually resulted in misunderstandings for the few readers who have had access to the rare journals where the series of articles (partly in Japanese) were published.

The purpose of this article is to amend the (largely unknown) analysis proposed by the Japanese school, going back to Ito's original idea, but including the precise and rigorous algebraic definitions that were missing in the previous literature, and provide a revised classification of monoarchetypal modular structures. Accordingly, and for ease of comparison, we adopt here the term "complex structure" used by Sadanaga [9] to indicate a modular structure. 
A monoarchetypal modular structure ("complex structure") is a three-dimensional triperiodic structure consisting of subperiodic modules ("substructures") which are either strictly identical or 158 nearly identical to each other in configuration. The complex structure is therefore determined by the structure of the module and the way in which the modules are arranged one with respect to the others.

We consider the operations mapping the various modules. These operations are of two types [9]:

1. local $(\lambda)$ operations: isometries mapping a module to itself; they are symmetry operations of the module, defined only for module on which they act, i.e. in the subspace spanned by the module itself;

2. partial $(\sigma)$ operations: isometries mapping different modules; a given partial operation is defined only for the pair of modules to which it applies and does not act elsewhere in the crystal space.

Exactly like the infinite number of atoms in a crystal structure is represented by the finite number in the unit cell, the infinitely many modules that build up a modular structure can be represented by a

finite number. If $G_{m}^{3}$ is the symmetry group of an $m$-periodic three-dimensional object $(m<3)$, a module can be fully contained in a unit cell only for $m=0$; when $m=1$ or $m=2$ the modules are rods (chains) or layers (sheets) respectively and are therefore infinite in one or two directions respectively so that a unit cell cannot actually contain any module. We can however identify a finite number of modules to a unit cell by counting the number of modules that cross the unit cell in the 3$m$ directions of missing periodicity, i.e. which are not related by a full lattice translation in that or 176 those direction(s). The other modules are then obtained by full lattice translations. In the following, we will denote the $\mathrm{i}$-th module as $\mathrm{X}_{\mathrm{i}}$ where $\mathrm{i}=0,1, \ldots, k$, so that $k+1$ modules are identified in the unit cell of the triperiodic structure. The subperiodic group of the i-th module, $G_{m, i}^{3}$, contains the local $(\lambda)$ operations of $\mathrm{X}_{\mathrm{i}}$ and constitutes its stabilizer (group of mappings that leave the module 
invariant); it will be indicated as $\mathrm{N}_{\mathrm{i}}$ for nucleus [19]. Further, let us denote a partial operation

mapping $\mathrm{X}_{\mathrm{i}}$ to $\mathrm{X}_{0}$ as $\Phi(\mathrm{i} \rightarrow 0)$. The target module of $\Phi(\mathrm{i} \rightarrow 0)$ is the reference module $\mathrm{X}_{0}$, whereas

the source module varies with i, i.e. the operations are meant to be applied from the left:

$$
\Phi(\mathrm{i} \rightarrow 0) \mathrm{X}_{\mathrm{i}}=\mathrm{X}_{0}
$$

The operation $\Phi(0 \rightarrow 0)$ maps $\mathrm{X}_{0}$ to $\mathrm{X}_{0}$, i.e. it is a local operation of $\mathrm{X}_{0}: \Phi(0 \rightarrow 0) \in \mathrm{N}_{0}$. The product of a local operation $\Phi(0 \rightarrow 0)$ and a partial operation $\Phi(\mathrm{i} \rightarrow 0)$ is again a partial operation that maps the same pair of modules for a different but equivalent configuration of the target module

$\mathrm{X}_{0}$. Hence, the product $\mathrm{N}_{0} \Phi(\mathrm{i} \rightarrow 0)$ is defined. The complete set of all the mappings to $\mathrm{X}_{0}$ obtained 188 by making $\mathrm{i}$ a running index gives what Loewy [20] has called the Mischgruppe of $\mathrm{X}_{0}$, denoted $\mathrm{M}_{0}$ below, a term which has received several translations. Hereafter we use the term mixed group suggested by Dixon [19], which is close to the original German ${ }^{2}$. For the sake of briefness, the notation $\Phi(\mathrm{i} \rightarrow 0)$ is simplified to $\Phi_{\mathrm{i}}$ whenever this does not lead to ambiguity. The mixed group of $\mathrm{X}_{0}$ is therefore defined as:

$$
\mathrm{M}_{0}=\cup_{\mathrm{i}} \mathrm{N}_{0} \Phi_{\mathrm{i}}
$$

The index $\mathrm{i}$ runs over all the infinite modules, but in the following we explicitly show only the interval $[0, k]$ of the modules identified in a single unit cell, the other modules being obtained by full lattice translations. When $\mathrm{i}=0$, the product $\mathrm{N}_{0} \Phi_{\mathrm{i}}$ is simply $\mathrm{N}_{0}$, the subperiodic group containing the 197 local operations of $\mathrm{X}_{0}$, because $\Phi_{0}=\Phi(0 \rightarrow 0) \in \mathrm{N}_{0}$. When $\mathrm{i} \neq 0, \mathrm{~N}_{0} \Phi_{\mathrm{i}}$ is the set of all the partial operations mapping any $\mathrm{X}_{\mathrm{i}} \neq \mathrm{X}_{0}(\mathrm{i}=1,2, \ldots, k)$ to $\mathrm{X}_{0}$. This set is called the shell of the mixed group $\mathrm{M}_{0}$, denoted $\mathrm{H}_{0}$. Incidentally, it does not form a group. The mixed group can therefore be decomposed into the nucleus and the shell:

$$
\mathrm{M}_{0}=\mathrm{N}_{0} \cup_{\mathrm{i}=1, k} \mathrm{~N}_{0} \Phi_{\mathrm{i}}=\mathrm{N}_{0} \cup \mathrm{H}_{0}
$$

The inverse of a partial operation $\Phi_{\mathrm{i}}=\Phi(\mathrm{i} \rightarrow 0)$ is the partial operation $\Phi_{\mathrm{i}}^{-1}=\Phi(0 \rightarrow \mathrm{i})$ that maps 203 $\mathrm{X}_{0}$ to $\mathrm{X}_{\mathrm{i}}$. The product of a partial operation $\Phi(0 \rightarrow \mathrm{i})$ and a local operation $\Phi(0 \rightarrow 0)$ is again a

2 To be noted that despite its name, a "mixed group" is not a group but a set of operations. 
partial operation that maps the same pair of modules for a different but equivalent configuration of the source module $\mathrm{X}_{0}$. Hence, the product $\Phi(0 \rightarrow \mathrm{i}) \mathrm{N}_{0}=\Phi^{-1}(\mathrm{i} \rightarrow 0) \mathrm{N}_{0}$ is defined. It follows that $\Phi_{\mathrm{j}}{ }^{-}$

${ }^{1} \mathrm{~N}_{0} \Phi_{\mathrm{i}}$ is defined as the set of all the partial operations mapping $\mathrm{X}_{\mathrm{i}}$ to $\mathrm{X}_{\mathrm{j}}$ via $\mathrm{X}_{0}$. If we take $\mathrm{j}=\mathrm{i} \neq 0$, this set becomes $\Phi_{i}^{-1} \mathrm{~N}_{0} \Phi_{\mathrm{i}}$ and contains all the operations mapping a module $\mathrm{X}_{\mathrm{i}} \neq \mathrm{X}_{0}$ to itself via $\mathrm{X}_{0}$.

Hence $\Phi_{\mathrm{i}}^{-1} \mathrm{~N}_{0} \Phi_{\mathrm{i}}$ is the set of the local operations of $\mathrm{X}_{\mathrm{i}}$, i.e. $\mathrm{N}_{\mathrm{i}}$. Indeed, $\Phi_{\mathrm{i}}^{-1} \mathrm{~N}_{0} \Phi_{\mathrm{i}}$ is simply the conjugation of $\mathrm{N}_{0}$ by $\Phi_{\mathrm{i}}$ and conjugation is a similarity transformation. All $\mathrm{N}_{\mathrm{i}}$ are isomorphic to each other, differing for the orientation and/or position in space of their symmetry elements.

$$
\Phi_{\mathrm{j}}^{-1} \mathrm{M}_{0}=\Phi_{\mathrm{j}}^{-1} \mathrm{~N}_{0} \cup \Phi_{\mathrm{j}}^{-1} \mathrm{H}_{0}=\Phi_{\mathrm{j}}^{-1} \mathrm{~N}_{0} \cup_{\mathrm{i}} \Phi_{\mathrm{j}}^{-1} \mathrm{~N}_{0} \Phi_{\mathrm{i}}=\Phi_{\mathrm{j}}^{-1} \mathrm{~N}_{0} \Phi_{\mathrm{j}} \cup_{\mathrm{i} \neq \mathrm{j}} \Phi_{\mathrm{j}}^{-1} \mathrm{~N}_{0} \Phi_{\mathrm{i}}=\mathrm{N}_{\mathrm{j}} \cup_{\mathrm{i} \neq \mathrm{j}} \Phi_{\mathrm{j}}^{-1} \mathrm{~N} \Phi_{\mathrm{i}}=\mathrm{M}_{\mathrm{j}}
$$

which is the set of all the local operations of $\mathrm{X}_{\mathrm{j}}$ (i.e. the subperiodic group, or nucleus $\mathrm{N}_{\mathrm{j}}$ ) and of the partial operations mapping any module but $\mathrm{X}_{\mathrm{j}}$ to $\mathrm{X}_{\mathrm{j}}$ (i.e. the shell $\mathrm{H}_{\mathrm{j}}$ ). In other words, $\Phi_{\mathrm{j}}{ }^{-1} \mathrm{M}_{0}$ is simply $\mathrm{M}_{\mathrm{j}}$, the mixed group of $\mathrm{X}_{\mathrm{j}}$. Then, $\mathrm{N}_{\mathrm{j}}$ and $\mathrm{H}_{\mathrm{j}}$ are the nucleus and the shell of $\mathrm{M}_{\mathrm{j}}$. Taking the union of all the mixed groups, we obtain the groupoid of the complex structure:

$$
\mathscr{D}=\cup_{\mathrm{i}} \mathrm{M}_{\mathrm{i}}=\cup_{\mathrm{ij}} \Phi_{\mathrm{j}}^{-1} \mathrm{~N}_{0} \Phi_{\mathrm{i}}
$$

Since the modules are all of the same type, the groupoid is connected and corresponds to the definition of Brandt [14]. D contains the complete set of all the operations mapping any pair of modules, $\mathrm{X}_{\mathrm{i}}$ and $\mathrm{X}_{\mathrm{j}}$, obtained by making not only $\mathrm{i}$ but also $\mathrm{j}$ a running index. The groupoid can be shown in a tabular form, where the index i runs on all the infinite modules. Exactly as in a space group the infinite number of symmetry operations can be represented by a finite set from which all the others are obtained by adding full lattice translations to the translations component of the representation $(\mathbf{W}, \mathbf{w})$, a groupoid can be represented by a finite table in which the index is limited to the $k+1$ modules identified in a single unit cell, i.e. not related by full lattice translations:

$$
\mathscr{D}=\begin{array}{rlccccccc}
\mathrm{N}_{0} & \cup & \mathrm{N}_{0} \Phi_{1} & \cup & \mathrm{N}_{0} \Phi_{2} & \cup \ldots \cup & \mathrm{N}_{0} \Phi_{\mathrm{i}} & \cup \ldots \cup \mathrm{N}_{0} \Phi_{k} \\
& \Phi_{1}^{-1} \mathrm{~N}_{0} & \cup & \mathrm{N}_{1} & \cup & \Phi_{1}{ }^{-1} \mathrm{~N}_{0} \Phi_{2} & \cup \ldots \cup & \Phi_{1}^{-1} \mathrm{~N}_{0} \Phi_{\mathrm{i}} \cup \ldots \cup \Phi_{1}{ }^{-1} \mathrm{~N}_{0} \Phi_{k}
\end{array}
$$




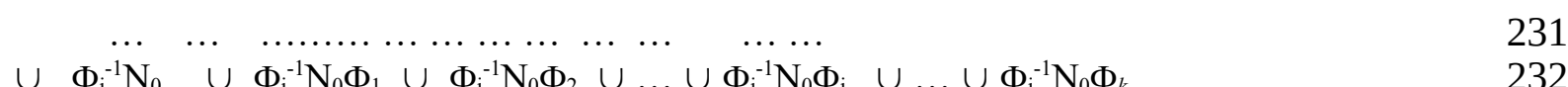

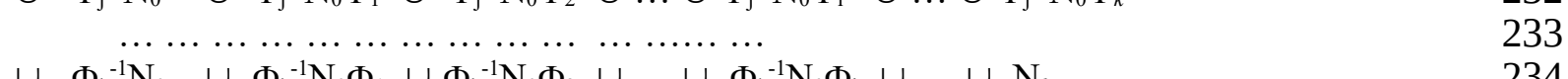

$\cup \Phi_{\mathrm{k}}^{-1} \mathrm{~N}_{0} \cup \Phi_{\mathrm{k}}^{-1} \mathrm{~N}_{0} \Phi_{1} \cup \Phi_{\mathrm{k}}^{-1} \mathrm{~N}_{0} \Phi_{2} \cup \ldots \cup \Phi_{\mathrm{k}}^{-1} \mathrm{~N}_{0} \Phi_{\mathrm{i}} \cup \ldots \cup \mathrm{N}_{k} \quad 234$

The finite table representing the groupoid is composed by $k+1$ lines, each representing a mixed

The operations in each mixed group map the various modules to the same target module. A partial complex structure, and the translations that correspond to the full lattice vectors of the complex

\section{The Japanese pioneering contribution to the classification of complex structures}

Let A be the archetype (Sadanaga's "fundamental structure") from which the modules X 
groupoid $\mathscr{D}_{\mathrm{C}}$ may actually degenerate into the space group of the complex structure $G_{\mathrm{C}}$ or not, 258 depending on whether all or only some of the local and partial operations have continuation in the 259 whole crystal space and define the corresponding global operations.

Ito $[17,18]$ was the first to recognize the presence of partial operations in crystal structures. Without 261 the mathematical background of Brandt [14] and Loewy [20], he nevertheless understood that a wider algebraic structure, going beyond space groups, was needed to completely describe complex structures. His approach was however essentially inductive and did not allow him to obtain a complete picture. The complex structures studied by Ito were called "polysynthetic structures" by analogy with the polysynthetic twinning occurring in minerals like albite, and the term "twinning" was used to describe the geometric relation between the modules, an unfortunate choice that later led to repeated confusion in the literature; this was eventually corrected to "cell-twinning" [3]. That the choice of wording was inherited from a parallelism with the case of twinning is evident from the terminology introduced by Ito himself. The space groupoids (term that was unknown to Ito) which describe the complex structures he studied were called twinned space groups; they were obtained in the following way ([18], page 2). called a twinning group, onto one of the space groups of Schoenflies. The domain of operation of a twinning group is always a multiple (or submultiple) of that of the original group. A new cell is formed, governed by the operation of the twinning group.

The unit cells (or multiple or submultiple thereof) of the original space group are so juxtaposed that only every other, instead of every, cell is in parallel and continuous position. At the boundary planes of the original cells twinned the operations of the twinning group prevail and those of original group are overridden by them and cease to be effective. [...] the symmetry elements that constitute the twinning group must be 
either digonal (rotation or screw) axes or reflexion [sic] (with or without a glide)

planes. Simple gliding must also be taken into account.

Although somewhat imprecise when judged from a contemporary perspective, Ito's definition can

be easily made more formal and rigorous. The "original group" is $G_{\mathrm{A}}$. The "twinning group", $G_{\mathrm{T}}$ in the following, whose "symmetry elements" can only be "digonal", is a group having as generator(s) operation(s) obtained by prolonging the partial operation(s) mapping the modules $\mathrm{X}$ to global operations. The "domain of operation" of $G_{\mathrm{T}}$ is the subspace of the crystal space on which the partial operations act. Depending on whether the module X spans the whole unit cell of the 289 fundamental structure A (Figure 2) or only party of it (Figure 3), the "domain of operation" of $G_{\mathrm{T}}$ is 290 "a multiple" or "a submultiple" of that of $G_{\mathrm{A}}$. In fact, a complex structure C being by definition composed by multiple copies of the module X, two situations may occur:

1. if only one copy of $\mathrm{X}$ can be identified in the unit cell of $\mathrm{A}$, then the unit cell of $\mathrm{C}$ is larger 293 than the unit cell of A. The operations mapping the various $\mathrm{X}_{\mathrm{i}}$ (operations of $G \mathrm{~T}$ ) act at the 294 boundaries of the unit cell of A and beyond, so that their "domain of operation" is a "multiple" of the unit cell of A (Figure 2);

2. if instead $\mathrm{X}$ is obtained as a cut from $\mathrm{A}$, there are necessarily partial operations mapping 297 modules $\mathrm{X}_{\mathrm{i}}$ that act on a region inside the unit cell of $\mathrm{A}$; this region is therefore a 298 "submultiple" of the unit cell of A (Figure 3). 

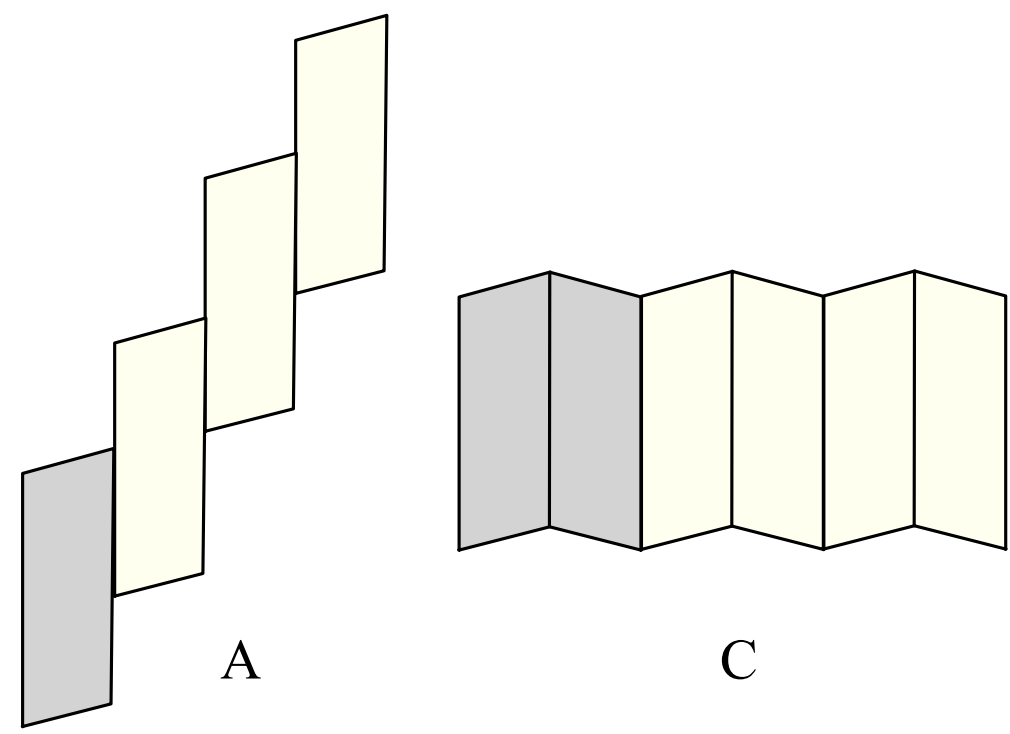

$\mathrm{C}$

Figure 2: Example of fundamental structure A (left) built by juxtaposing modules $X$ in a monotonous way. The unit formula of A corresponds to a single instance of $\mathrm{X}$, so that the repetition period of A (grey region) is one-module thick (X). The complex structure $\mathrm{C}$ (right) is obtained by acting with a mirror reflection on $\mathrm{X}$ on the boundary of the unit cell of $\mathrm{A}$. As a result, the repetition period of $\mathrm{C}$ corresponds to two modules $\left(\mathrm{X}_{2}\right)$. Accordingly, the unit cell of $\mathrm{C}$ is twice larger than that of $\mathrm{A}$. The grey regions identify the modules in a single unit cell; the unit cell itself is not drawn). 


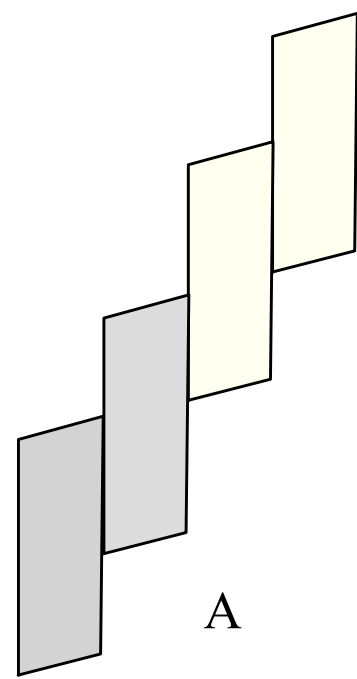

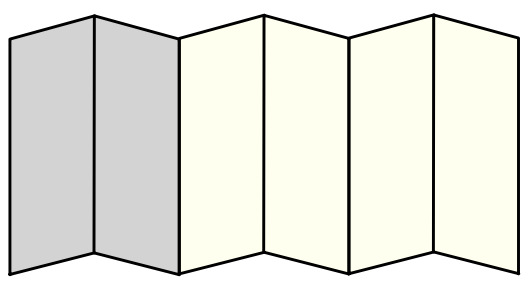

$\mathrm{C} 1$

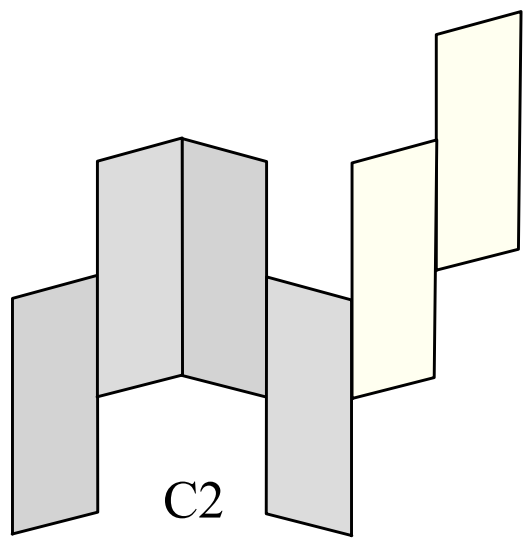

$\mathrm{C} 2$

Figure 3: Example of fundamental structure A (left) built by juxtaposing modules $\mathrm{X}$ in a monotonous way. The unit formula of A corresponds to two instances of $X$, so that the repetition period of $\mathrm{A}$ (grey region) is two-module thick $\left(\mathrm{X}_{2}\right)$. Examples of modular structures whose shortest repetition period consists of two modules can be found in all layer structures with the topology of close packing of spheres. The complex structure $\mathrm{C} 1$ (middle) is obtained by acting with a mirror reflection on $\mathrm{X}$ in the middle of the $\mathrm{A}$. As a result, the repetition period of $\mathrm{C}$ corresponds to two modules $\left(\mathrm{X}_{2}\right)$ and the unit cell of $\mathrm{C}$ has the same width as that of A. The complex structure C2 (right) is obtained by acting with a translation and then with a mirror reflection on $\mathrm{X}$. As a result, the repetition period of $\mathrm{C}$ corresponds to four modules $\left(\mathrm{X}_{4}\right)$ and the unit cell of $\mathrm{C}$ is twice larger than that of $\mathrm{A}$.

An example of case 2 above is found in pyroxenes, which were also the starting point of Ito's

research [15]. Clinoenstatite (the "fundamental structure" A), protoenstatite and orthoenstatite (two

“complex structures" C) can be synthetically represented as $\mathrm{X}_{2}^{+}, \mathrm{X}^{+} \mathrm{X}^{-}, \mathrm{X}_{2}^{+} \mathrm{X}_{2}^{-}$, respectively, where "+" or "-" indicate the displacement of the $\mathrm{SiO}_{3}$ chains either $+c / 3$ or $-c / 3$ along the $a$ axis of the

The statement that the operations of $G_{\mathrm{T}}$ "prevail" over those of $G_{\mathrm{A}}$ "[a]t the boundary planes of the 
not appear in $G_{\mathrm{C}}$. They are replaced by operations of $\mathscr{D}_{\mathrm{C}}$, which, prolonged to global operations, appear in $G_{\text {т. }}$ The nature of the groupoid was clearly present, although in rather vague terms, in Ito's

A twinned space group may be identical with one of the 230 space groups of

Schoenflies. Theoretically, however, this is not always the case and happens only when certain geometrical requisites are fulfilled by the original lattice. Generally we find that a twinned space group is very near, but distinctly different from, one of the space groups of Schoenflies, containing certain symmetry elements in excess. This is due to the difference of domain of operation of the twinning group and the original space group, upon which it acts to produce a twinned space group.

Translated in modern language and correcting some confusion in the language ("symmetry elements" when the "symmetry operations" are actually meant), the above statement says that the groupoid $\mathscr{D}$ ("twinned space group") can degenerate to a space group, and therefore coincide with $G$ ("may be identical with one of the 230 space groups"); this happens when all the partial operations have a continuation in the whole crystal space. Otherwise, $\mathcal{D}$ contains partial operations ("certain symmetry elements in excess") that do not have a continuation ("due to the difference of domain of operation"). In symbols, Ito's definition corresponds to Equation (7) provided that $\mathcal{D}$ is renamed "twinned space group" and the operations $\Phi_{i}$ are the isometries that, if prolonged to global operations, generate the "twinning group" $G$ т. The OD idea of family structure was, in a nutshell, already present in Ito's mind: his "twinning group" would appear in the group of the family structure is all the possible partial operations, rather than those occurring in a specific structure, were used to build it.

Depending on the nature of the partial operation expressed in the basis of the modular structure, two scenarios become possible, that were later recognized by Sadanaga [9]: 
1. partial operations correspond to $q=1(\tau=\mathbf{t})($ Eq. 2$)$; when they are prolonged to global operations, the group they generate not only corresponds to one of the 230 crystallographic types, but its unit cell coincides with that $G_{\mathrm{C}}: \mathcal{T}\left(G_{\mathrm{T}}\right)=\mathcal{T}\left(G_{\mathrm{C}}\right)$.

2. partial operations correspond to $q>1(\tau=\mathbf{t} / p)$ (Eq. 2$)$; when they are prolonged to global operations, the group they generate has a unit cell that is a submultiple of that of $G_{c}$, so that the translation subgroup of $G_{\mathrm{T}}$ is a supergroup of the translation subgroup of $G_{\mathrm{C}}: \mathcal{T}\left(G_{\mathrm{T}}\right) \supset$ $\mathcal{T}\left(G_{\mathrm{C}}\right)$.

Ito's "twinning group" was restricted to digonal operations and by definition fell in case No. 1 above. A further restriction imposed by Ito [17] is that the "twinning group" $G_{\mathrm{T}}$ and the space group of the complex structure $G_{\mathrm{C}}$ do not contain operations with the same linear part $\mathbf{W}$ whose symmetry elements are parallel. This unnecessary restriction comes from the analogy with the case of twins, in which the orientation of the individuals (domains) are related by operations that cannot belong to the point group of either individual.

Sadanaga attempted to provide a more precise definition of "twinned space group", and in doing so he actually ended up extending and generalizing Ito's results. Sadanaga $[21,22]$ considered a structure consisting of substructures which are either strictly equal or nearly equal to each other in 353 configuration (which means only one type of module, possibly ignoring small differences due, e.g. to atomic substitutions) and called it a superstructure, a collective name to indicate both the fundamental and the complex structures, all made up by the same type of substructures. Removing the restriction imposed on the "twinning group" $G_{\mathrm{T}}$ by Ito [17], Sadanaga [9] identified the substructure (module) in the complex structure as a cut from the fundamental structure (archetype). He realised that the full symmetry of the complex structure can be described by a space groupoid, a special case of which is Ito's "twinned space group". Unfortunately, his definitions in different papers, but also within the same paper, are contradictory and easily bring confusion in the reader. In 
particular, the shell (for which Sadanaga more often used the term "hull": see [23] for a brief terminological survey) was not uniquely defined. In his papers we find two definitions.

D1. Sadanaga [9], caption of Figure 3 (where substructures are schematically represented by triangles), says that "the set of all operations that bring every triangle into superposition upon another constitutes the hull"; the same definition is found also in [21, 22];

D2. the same paper, right below Eq. 2, states that " $h_{\mathrm{i}}^{\prime}$ 's are the elements of $H$ " where $h_{\mathrm{i}}\left(\Phi_{\mathrm{i}}\right.$ in Eq. 3) are the partial operations which, applied to the nuclei $\mathrm{N}_{\mathrm{i}}$, build up the "hull" (shell) 368 $H$, suggesting therefore that, contrary to the definition above, the latter is composed not by 369 “all [partial] operations" but only by the representatives.

From the analysis of some concrete structures, he classified "complex structures" in two categories, depending on whether "every member is derived by a twinning group operating on the unit cells (or multiples or submultiples thereof) of the fundamental structure [...]" or "the set of complex 373 structures contains a structure that has no twinning group to derive it from the fundamental 374 structure" [9]. The twinning group was defined as the set-theoretical union $\mathrm{e} \cup H$, where e is the 375 identity operation (which is required to for a group but is obviously not found among the partial, i.e. $\sigma$, operations) and $H$ is "hull" (shell). Clearly, if $H$ contains operations corresponding to $q>1$ in Eq. 377 2, then $H$ cannot form a group, even supplemented by the identity. A group can instead be obtained if the partial operations in definition D2 above are used as generators: in this case, there is no need 379 to add the identity, because the set of generators includes, for each operation, also its inverse, and 380 therefore the identity as well, Therefore, Sadanaga's classification of monoarchetypal modular 381 structures can be rationalized as follows:

1. polysynthetic structures, later renamed "Ito twins" [3], if the operation in $H$ generate a group with the same translation sublattice as the resulting modular structure; this group generated in this way corresponds to Ito's "twinning group"; 
2. polytypes, if $H$ contains operations corresponding to $q>1$ in Eq. 2, so the group generated

by them has a translation sublattice which is a superlattice of that of the resulting modular

structure.

The choice of the term "polytypes" to cover isochemical monoarchetypal modular structures exclusive of "polysynthetic structures" was unfortunate, because its meaning is more restricted with respect to the first official definition presented one year before [24], which covers both categories. A more serious problem occurs however when we compare the definition of "hull" and that of "twinning group". In this respect, definition D1 is clearly incorrect, because it corresponds to extracting from the groupoid all the partial $(\sigma)$ operations. However, with the exception of the trivial case $\mathrm{N}_{\mathrm{i}}=1$, the set-theoretical union of partial operations does not form a group, even when it is supplemented by the identity. In fact, a group must be closed under any combination of the elements of the set. The groupoid contains all the partial operations $\Phi_{s}(i \rightarrow 0)$ and all the partial operations $\Phi_{\mathrm{t}}(0 \rightarrow \mathrm{j})=\Phi_{\mathrm{t}}^{-1}(\mathrm{j} \rightarrow 0)$. For $\mathrm{i}=\mathrm{j}$ the combination $\Phi_{\mathrm{s}}(0 \rightarrow \mathrm{i}) \Phi_{\mathrm{t}}(\mathrm{i} \rightarrow 0)$ is a local operation of $\mathrm{N}_{\mathrm{i}}$ and the combination $\Phi_{\mathrm{s}}(\mathrm{i} \rightarrow 0) \Phi_{\mathrm{t}}(0 \rightarrow \mathrm{i})$ is a local operation of $\mathrm{N}_{0}$. However, with the 399 exception of the identity, the "twinning group" does not contain any local operation, as it turns out 400 to be the case for definition $\mathrm{D} 1$, unless $\mathrm{N}=1$ or $\mathrm{s}=\mathrm{t}$.

Definition D2 does instead provide a group if, for each pair of substructures (modules), one 402 representative $\Phi_{\mathrm{s}}(\mathrm{i} \rightarrow 0)$ is selected as generator. In this case, in fact, the only local operations that 403 are obtained by combining partial operations $\Phi_{\mathrm{s}}(0 \rightarrow \mathrm{i}) \Phi_{\mathrm{s}}(\mathrm{i} \rightarrow 0)$ and $\Phi_{\mathrm{s}}(\mathrm{i} \rightarrow 0) \Phi_{\mathrm{s}}(0 \rightarrow \mathrm{i})$ are the 404 identities of the respective nuclei, which always have a continuation in the whole crystal space: the 405 only identity operation of the "twinning group" $G$ r. Ito's idea of "twinning group" as formalized by 406 Sadanaga corresponds therefore to definition D2.

For the case of complex structures that were called "polytypes", Sadanaga used the term 408 "polytypism groupoid" for e $\cup H$ instead of "twinning group" to emphasize that these operations do 409 not form a group. However, if we adopt definition D2, for consistency, a group is always obtained 
by using partial operations as generators but, because of the unusual translation component of the

partial operations, the basis vectors of this group differ from those of the space group $G$ c. In fact, $q$

$>1$ in Eq. (2) means that $\tau<\mathbf{t}$, i.e. the periodicity defined by the partial operations, once prolonged

to global operations, is shorter than the periodicity of the space group $G_{\mathrm{c}}$. Sadanaga's classification

does therefore make sense, but needs to be reformulated. For that, we re-analyse the same examples

used by Sadanaga [9] as well as the simpler but enlightening example of the hcp polytype of sphere

packing.

\subsection{The modular structure of boleite and pseudoboleite}

Pseudoboleite, $\mathrm{Pb}_{31} \mathrm{Cu}_{24} \mathrm{Cl}_{62}(\mathrm{OH})_{48}$, is a rare secondary mineral commonly occurring as intergrowths

with and as parallel overgrowths on boleite, $\mathrm{KPb}_{26} \mathrm{Ag}_{9} \mathrm{Cu}_{24} \mathrm{Cl}_{62}(\mathrm{OH})_{48}$. The former is tetragonal,

space-group type $I 4 / \mathrm{mmm}$, cell parameters $a=15.24 \AA, c=30.74 \AA$ [25]. The symmetry of boleite

has long been a subject of discussion. C. Friedel [26] defined it as cubic, whereas G. Friedel [27]

strongly denied even a cubic pseudo-symmetry and attributed to boleite a tetragonal symmetry with

c/a ratio of 4. Hadding [28] classified boleite as cubic, and Gossner and Arm [29] assigned it to a

space group of type $\operatorname{Pm} \overline{3} m$. G. Friedel [30] replied insisting on his idea of tetragonal symmetry,

crystal, confirmed Friedel's interpretation [30], but Gossner [32] contested his conclusions on the

basis of a larger number of collected diffractions. The matter was eventually settled much later, 
$=60.82 \AA$. The structure he reported corresponds to a cell-twin of four cubic unit cells alternately related by mirror reflections and $z=1 / 4$ and $z=3 / 4$ and an $n$-glide reflection at $z=1 / 2$ (Figure 4). 437 Sadanaga [9], probably unaware of the work by Rouse [33], adopted Ito's description, but in his groupoid analysis he used $\operatorname{Pm} \overline{3} m$ as nucleus $\mathrm{N}_{0}$, which is incorrect because a substructure is by definition subperiodic and therefore the nucleus must correspond to a subperiodic group, not to a space group. Sadanaga chose $m x, y, 1 / 4$ (incorrectly indicated as mirror reflection at $c / 8$ instead of $c / 4)$ and $\mathrm{t}(1 / 2,1 / 2,1 / 2)$ as partial operations: the latter results from the product of $m x, y, 1 / 4$ and $n x, y, 1 / 2$ (operations meant to be applied from the left). The tabular expression of the groupoid, Eq. 3 in Sadanaga [9], is a $3 \times 3$ matrix instead of a $4 \times 4$ as it should be considering the interpretation of boleite: this is because only one mirror reflection, at $m x, y, 1 / 4$ was explicitly considered: the one at $x, y, 3 / 4$ was not included, as it should be if the tabular expression of the groupoid has to include operations mapping modules identified in the same unit cell. Despite these errors, his analysis is nevertheless worth considering because it gives a clue to understand the classification he proposed. Sadanaga placed the groupoid obtained in this way in the category of "twinned space groups", stating that "e $\cup H \cong I m$ ". As already discussed above, a group of type Im can be obtained by considering one partial operation for each pair of substructures $(i, 0)$, as well as its inverse; for example, in the case under consideration the operations 1 (identity), $\mathrm{t}\left(\overline{\left.1 / 2 \frac{1}{2} / \frac{1}{2}\right)}\right), m x, y, 1 / 4, m x, y, 3 / 4$, all digonal, as well the operations obtained by adding full lattice translations (which are not shown explicitly in the tabular for of the groupoid). This result corresponds to definition D2. 

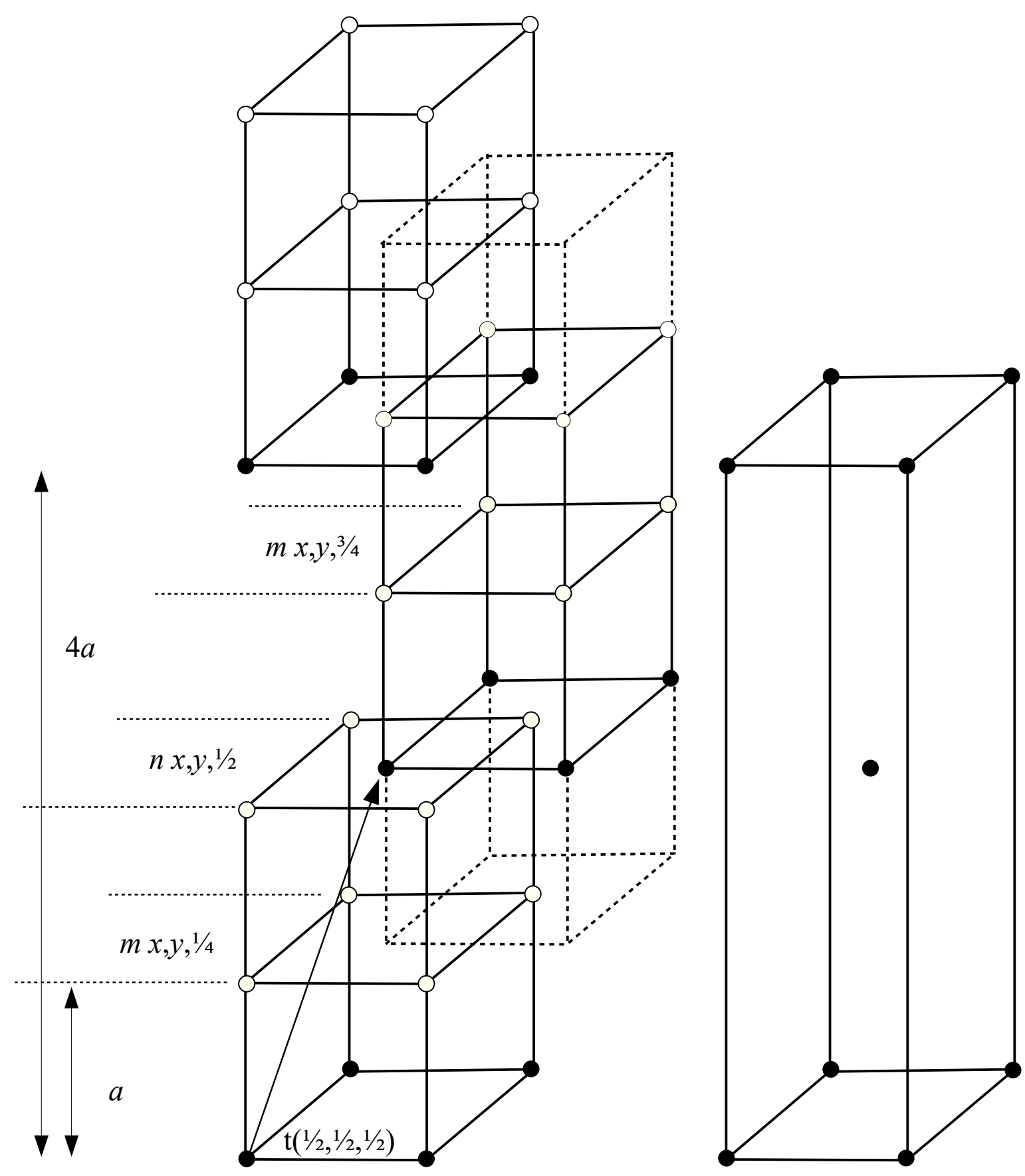

Figure 4: The structure of boleite as imagined by Ito [18] and Sadanaga [9], on the left, built by stacking a cubic unit cell, with partial operations $m x, y, 1 / 4, n x, y, 1 / 2, m x, y, 3 / 4$. The translation $\mathrm{t}(1 / 2,1 / 2,1 / 2)$ is obtained as combination of the first two operations and is prolonged to global operation, resulting in the $t l$ unit cell on the right. White lattice nodes represent an intermediate step in the construction of the $t l$ unit cell and do not appear in the latter, because they do not correspond to any global operation. The cubic unit cell was assigned to percylite, later discredited, whereas it actually corresponds to boleite itself. The $t I$ unit cell corresponds to an old model of boleite (see the history of boleite structure determination in the text). 
The structure of boleite is however cubic, not tetragonal, and we have to show that boleite and pseudoboleite are built by the same layer, stacked differently. When extracting the layer, one of the three cubic axes of boleite becomes the direction of missing periodicity for the layer. In the following, we take the cubic $c$ axis as this direction. Boleite and pseudoboleite are then obtained by translating this layer along the cubic [001] and [111] directions respectively. First of all, we need to show that these two structures do have a common substructure. Boleite is the fundamental structure 465 A with a single module identified in the unit cell; pseudoboleite is the complex structure $\mathrm{C}$ with two 466 modules identified in the unit cell. To compare the two structures, we express them in the common 467 maximal subgroup, which is of type $P 4 / \mathrm{mmm}$ and is obtained in the following way. The structure of 468 pseudoboleite is expressed in the klassengleiche subgroup of index 2 obtained by removing the $I$ centring translation. A model of pseudoboleite can be obtained from the module of boleite in the 470 following way.

1. The structure of boleite is expressed in the $P 4 / \mathrm{mmm}$ general subgroup (index 6) from $P m \overline{3} m$ 472 obtained by basis change $\mathbf{a}, \mathbf{b}, 2 \mathbf{c}$ with origin shift $0,0,1 / 2$ (the origin shift is required to match the $z$ coordinates of the corresponding atoms in the two minerals).

2. The upper part $(z>1 / 2)$ of the structure, which corresponds to a single module of boleite and is related to the lower part by a translation of $c / 2$, is shifted by a $C$-centring vector, which is tantamount to take an $I$-translated copy of the lower part.

In this setting, the model of pseudoboleite obtained from boleite can be compared with the structure 478 of pseudoboleite, with a 1:1 correspondence of atomic sites (Table 1: hydrogen atoms are not 479 included because of the uncertainty on their position). For such a comparison, one needs to:

1. ignore the difference in the chemical nature for some cations: $\mathrm{K}$ and $\mathrm{Ag}$ in pseudoboleite are all replaced by $\mathrm{Pb}$ in the model obtained from boleite;

2. one $\mathrm{OH}$ site in pseudoboleite is replaced by one $\mathrm{Cl}$ site in the model obtained from boleite and vice-versa. 

building the two structures, boleite and pseudoboleite cannot be considered polytypes, but rather

Having shown that the two structures are indeed built by the same type of module, once some identity, $\Phi_{1}=\mathrm{t}(\overline{1 / 2 / 1 / 2 / 2})$, and $\mathrm{N}_{0}=P(4 / m) m m$ (Table 2$)$.

For the diagonal terms, conjugation of $P(4 / m) m m$ with the partial operation $\left\{1 \mid \overline{1 / 2} \frac{1 / 2}{1 / 2}\right\}$ gives back $P(4 / \mathrm{m}) \mathrm{mm}$ modulo a full lattice translation. This means that all the local operations in two modules

\subsection{The modular structure of zoisite and clinozoisite}

Clinozoisite $\mathrm{Ca}_{2} \mathrm{Al}_{3}\left(\mathrm{SiO}_{4}\right)\left(\mathrm{Si}_{2} \mathrm{O}_{7}\right) \mathrm{O}(\mathrm{OH})$, is a calcium aluminium hydroxy sorosilicate belonging to 
which is no longer considered a member of the epidote group [40]: it crystallises in a space group of

type Pnma, with cell parameters $a=16.212 \AA, b=5.555 \AA$ and $c=10.034 \AA$ [39]. Clinozoisite

corresponds to the fundamental structure A in which only one module is identified in the unit cell.

Zoisite corresponds to a complex structure $\mathrm{C}$ with two layers identified in the unit cell (cfr. Figure

Ito [18] established a metric relation between the two minerals noting that $2 a_{\text {clino }} \cos \left(\beta_{\text {clino }}-\pi / 2\right)=$

$a_{\text {zoisite }}{ }^{3}$. This metric relation does not represent, however, a valid change of basis: the corresponding direction, perpendicular to the $c$ axis, would be irrational in the unit cell of clinozoisite, whereas the closest transformation, $\mathbf{a}_{\text {zoisite }}=2 \mathbf{a}_{\text {clino }}+\mathbf{c}_{\text {clino }}$, leads to a $\beta_{\text {zoisite }}$ angle of about $81^{\circ}$ instead of $90^{\circ}$. Nevertheless, if we ignore this significant angular deviation, we can follow Ito's original reasoning and Sadanaga's development. Similarly to what has been done for the case boleite-pseudoboleite, we build a structural model of zoisite from that of clinozoisite in the following way.

1. The structure of clinozoisite is expressed in the isomorphic $P 12_{1} 1 / m$ subgroup (index 2) obtained by basis change $2 \mathbf{a}, \mathbf{b}, \mathbf{c}$ with origin shift $1 / 2,0,0$ (the origin shift is required to match the $x$ coordinates of the corresponding atoms in the two minerals).

2. The module common to the two dimorphs is located in the region $1 / 4 \leq x \leq 3 / 4$; the model of the structure of zoisite is obtained by applying an $n$-glide reflection to this module at $1 / 4, y, z$.

In this case, the matching of atomic positions is somewhat more approximate, because of the difference in the $\beta$ angle mentioned above. Nevertheless, the atomic pairing in Table 3, which corresponds to a maximal and average distance between corresponding atoms of $0.7423 \AA$ and module, although it undergoes some degree of desymmetrization [41] in the real structure.

3 Ito actually used the cell parameters of epidote, isostructural with clinozosite; moreover, he incorrectly wrote $\cos \beta_{\text {epidote }}$ instead of $\cos \left(\beta_{\text {epidote }}-\pi / 2\right)$. 
axis in the case of clinozoisite and an $n$-glide reflection at $1 / 4 y z$ in the case of zoisite. The groupoid

corresponding to the structure of zoisite is obtained by the set-thoretical union $\cup_{\mathrm{i}, \mathrm{j}=[0,1]} \Phi_{\mathrm{j}}^{-1} \mathrm{~N}_{0} \Phi_{\mathrm{i}}$

where $\Phi_{0}$ is the identity, $\Phi_{1}=\left\{m_{100} \mid \frac{1 / 2}{1 / 21 / 2}\right\}$, and $\mathrm{N}_{0}=P(1) 2_{1} / m 1$ (Table 4).

Similarly to the case of pseudoboleite, all the operations have a continuation in the whole crystal space and are prolonged to global operations. The result is a space group of type Pnma, which is

precisely that of zoisite. As the case of pseudoboleite, the groupoid of zoisite $\mathscr{D}_{\mathrm{C}}$ degenerates to

Sadanaga [9] placed this groupoid again in the category of "twinned space groups", stating that that

“e $\cup H \cong P n "$. This is again correct only if $H$ corresponds to definition D2.

\section{Polytypes beyond Ito twins}

Space groupoids contain of all the isometries mapping substructures in the superstructure. All these isometries need not correspond to $q=1$ (Eq. 2). When it is the case, they correspond to Ito's idea of

"twinned space group" and his "twinning group" is then defined as the group having as generators the partial operations mapping the various modules. On the contrary, the presence of isometries which correspond to $q>1$ is realized when the intrinsic translational part of the operation (screw or glide component) is not compatible with the period of the structure. This was realized by Sadanaga [9] in the case of of the $6 \mathrm{H}$ polytype of $\mathrm{SiC}$.

Polytypes based on the close packing of equal spheres are obtained by three-dimensional stacking

of diperiodic close packed sphere sheets according to the well known A-B-C mode. Spheres of 
missing periodicity of the layer. Filling the cavities formed by stacking of layers leads to a large

number of derivative structures [42].

The partial operations mapping two successive layers are $t\left(2 / 3{ }^{1 / 3} \mathbf{c}_{0}\right)$ for the stacking $A \rightarrow B$ (or $B \rightarrow$

$\mathrm{C}$ or $\mathrm{C} \rightarrow \mathrm{A})$ and $\mathrm{t}\left(1 / 32 / 3 \mathbf{c}_{0}\right)$ for the stacking $\mathrm{A} \rightarrow \mathrm{C}\left(\right.$ or $\mathrm{C} \rightarrow \mathrm{B}$ or $\mathrm{B} \rightarrow \mathrm{A}$ ), where $\mathbf{c}_{0}$ is the

perpendicular distance between the plane of the layers. Sadanaga [9] considered the $3 C$ polytype of

$\mathrm{SiC}$ (sequence $\mathrm{ABC}$ ) as fundamental structure, and the $6 H$ polytype (ABCACB) as complex

structure. The latter can be obtained from the former through a reflection $m x, y, 1 / 2$ which transforms

ABC to CBA followed by a translation $1 / 32 / 30$ which transforms CBA to ACB. The partial operation

would therefore be $\left\{\left.m_{001}\right|^{1 / 3} 3^{2} / 31\right\}$, or $g(1 / 32 / 30) x, y, 1 / 2$ in Hermann-Mauguin notation, for which $q=3$

(Eq. 2). Sadanaga [9] concluded that "the reflection followed by the shift will not produce an

ordinary glide·reflection, because the length of the shift is neither a half nor a quarter of the period

in that direction". However, if the partial operation $\left\{\left.m_{001}\right|^{1 / 3} 3^{2} / 31\right\}$ is prolonged to a global operation, it

does generate a group, which is $H 11 \mathrm{~m}$, whose translations sublattice, because of the $H$ centring, is a
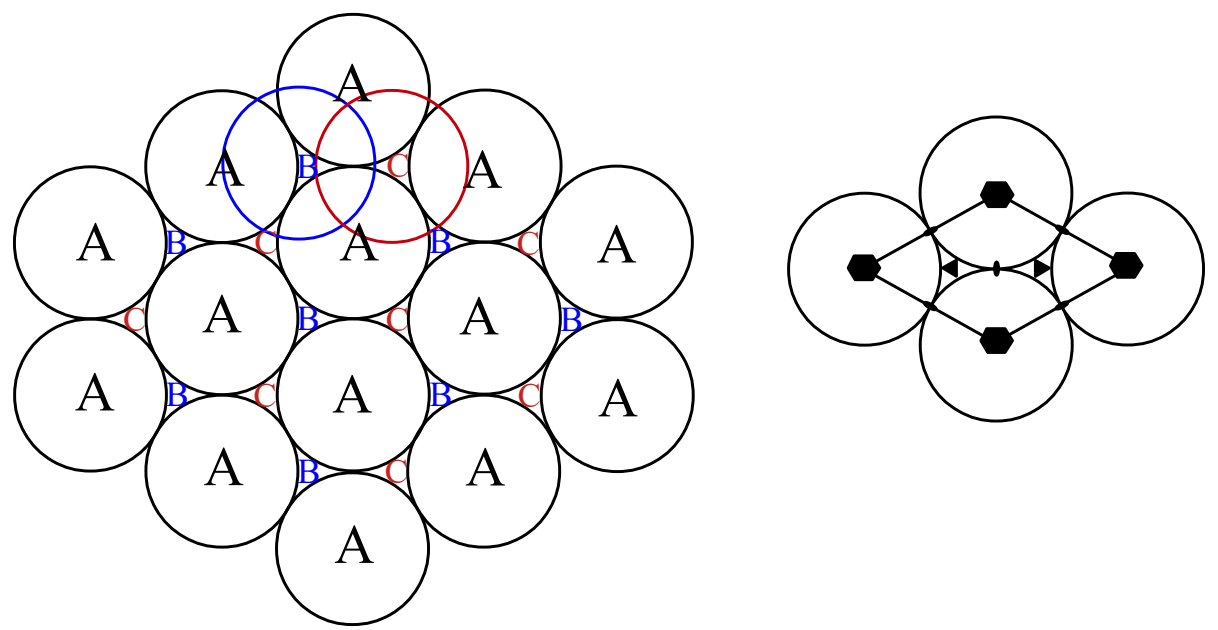

Figure 5: (Left) Geometry and notation of close packing of equal spheres. If the first layer is labelled A, two types of triangular cavities, $\mathrm{B}$ and $\mathrm{C}$, with opposite orientation, exist. Positions indicated by the same letter are translationally equivalent, whereas positions indicated by different letters are not. (Right) A diperiodic close packed equal sphere sheet and its rotational symmetry elements acting on the plane of the sheet. 
An even simpler example is represented by the $\mathrm{AB}$ polytype of sphere packings, which can be considered as a complex structure obtained from a fundamental structure having a period of only one layer, $\mathrm{A}$. In the $\mathrm{AB}$ polytype, the period corresponds to two layers and the partial operation is $\mathrm{t}\left(\overline{\left(2 / 3^{1 / 3} 3^{1 / 2}\right)}\right.$, which maps $\mathrm{B}$ onto $\mathrm{A}$. We can derive the groupoid of $\mathrm{AB}$ polytype by set-theoretical union $\cup_{\mathrm{i}, \mathrm{j}=[0,1]} \Phi_{\mathrm{j}}^{-1} \mathrm{~N}_{0} \Phi_{\mathrm{i}}$ where $\Phi_{0}$ is the identity, $\Phi_{1}=\mathrm{t}\left(\overline{2 / 3^{1 / 3} / 2}\right)$, and $\mathrm{N}_{0}=P(6 / m) m m$.

$$
\begin{aligned}
& \mathcal{D}_{\mathrm{C}}=P(6 / m) m m \quad P(6 / m) m m \mathrm{t}\left(\overline{2 / 3^{1 / 3} 3^{1 / 2}}\right) \\
& \mathrm{t}\left(2 / 3^{1 / 3} 1 / 2\right) P(6 / m) m m \quad \mathrm{t}\left(2 / 3^{1 / 3} 3^{1 / 2}\right) P(6 / m) m m \mathrm{t}\left(\overline{2 / 3} 1^{1 / 3} 1 / 2\right)
\end{aligned}
$$

The diagonal terms correspond to the two nuclei, $\mathrm{N}_{\mathrm{A}}=P(6 / m) m m$ and $\mathrm{N}_{\mathrm{B}}=\mathrm{t}\left(2 / \frac{1}{3} / \frac{1}{3} / 2\right) P(6 / m) m m$ $\mathrm{t}\left(\overline{\left(2 / 3^{1 / 3} / 2\right.}\right)$, i.e. the conjugation of $\mathrm{N}_{\mathrm{A}}$ by the partial operation. The 24 operations of $\mathrm{N}_{\mathrm{B}}$ (modulo the full lattice translations) are explicitly listed in Table 5, where operations in bold differ from those in $\mathrm{N}_{\mathrm{A}}$ by full lattice translations. This means that the corresponding operations in $\mathrm{N}_{\mathrm{A}}$ have a continuation in $\mathrm{N}_{\mathrm{B}}$, so that the diperiodic group of the layer pair therefore $P(\overline{6}) m 2$. Because the 583 layers are stacked in an alternate way (A always followed by B, B always followed by A), every 584 layer pair has the same diperiodic group $P(\overline{6}) m 2$ so that all together the operations of this layer 585 group are prolonged to global operations for the three-periodic polytype.

The next step consists in finding the operations in the extra-diagonal terms of the groupoid which 587 also have continuation and therefore are prolonged to global operations. Because $P(\overline{6}) m 2$ is a 588 normal subgroup of $P(6 / \mathrm{m}) \mathrm{mm}$ (the basis vectors being in common, the index of the subgroup in the 589 group is 2 , which means that the subgroup is necessarily normal), all the operations in one of diagonal terms are present also in the other (up to translation): extending $P(\overline{6}) m 2$ by any operation gives back a holohedral group. We therefore know that the space group is holohedral. There are however four types of holohedral hexagonal space group: $P 6 / \mathrm{mmm}, P 6 / \mathrm{mcc}, \mathrm{Pb}_{3} / \mathrm{mcm}$ and $P 6_{3} / \mathrm{mmc}^{2}$ (No. 191 to 194). To find which one corresponds to the AB polytype one has to check the translation parts of the operations in the extra-diagonal terms of the groupoid which are prolonged to global operations. Table 6 shows the twelve operations obtained as $P(\overline{6}) m 2 \mathrm{t}\left(\overline{2 / 3^{1 / 3} 3^{1 / 2}}\right)$ in the first 
column, and those obtained as $P(\overline{6}) m 2 \mathrm{t}\left(\overline{2 / 3^{1 / 3} 3^{1 / 2}}\right)$ in the second column, i.e. the set of $\Phi(\mathrm{B} \rightarrow \mathrm{A})$ and

$\Phi(\mathrm{A} \rightarrow \mathrm{B})$ operation the differ by a full lattice translation and, therefore, have a continuation. The

whole set of global operations obtained in the two steps above correspond to $P 6_{3} / m m c$, in an uncommon setting obtained by a shift of the origin of $1 / 3^{2} / 3 / 4$ as it can be verified by conjugating the 600 matrices representing the symmetry operations of this group with $t\left(1 / 3^{2} / 3^{1 / 4}\right)$. This shift of the origin 601 transforms the coordinates of the A and B layers from $(000)$ and $(2 / 31 / 31 / 2)$ respectively to $\left(\overline{1 / 3} 1 / 3{ }^{1 / 4}\right)$ and 602 $\left(1 / 3^{1 / 3}{ }^{1} / 4\right)$, i.e. positions $2 d$ and $2 c$ in $P 6_{3} / m m c$, which are precisely the atomic positions of the $h c p$ 603 structure.

Let us now concentrate on the partial operations in the groupoid that do not have a continuation and 605 are not prolonged to global operations (Table 7). In the groupoid of the AB polytype, the partial operations correspond to $q=3$ in Eq. (2) and require six application to obtain an operation of type (I,t) i.e. a period three times larger that that of the AB polytype (six layers). These operations do not correspond to a standard Hermann-Mauguin symbol. For instance, the four three-fold screw rotations parallel to the hexagonal [001] direction $\left(\left\{\left.3^{+} 001\right|^{1 / 3^{1 / 3} / \frac{1}{2}}\right\},\left\{\left.3_{001}^{-}\right|^{1 / 3^{2} / 3^{1 / 2}}\right\},\left\{\left.3^{+}{ }_{001}\right|^{2 / 3} 3^{1 / 3} 3^{1 / 2}\right\}\right.$ and $\left\{3^{-}\right.$ $\left.\left.001\right|^{2 / 3} 3^{1 / 3} / 2\right\}$ ) have a screw component of $\pm 1 / 2$. They can noted as $3_{ \pm 3 / 2}$ meaning a $360^{\circ} / \mathrm{N}$ rotation with $m / \mathrm{N}$ translation part noted as $\mathrm{N}_{m}$. The three twofold partial rotations in the (001) plane, $\left.\left\{\left.2_{1 \overline{0}}\right|^{2 / 3} 3^{1 / 3}\right]_{2}^{1 / 2}\right\}$, $\left\{\left.2_{210}\right|^{2 / 3} 3^{1 / 3}{ }^{1 / 2}\right\}$ and $\left\{\left.22_{120}\right|^{2 / 3} 3^{1 / 3} 1 / 2\right\}$ have a screw component of $1 / 6$ (the first two) and $1 / 3$ (the latter) and can be noted as $2_{1 / 3}$ or $2_{2 / 3}$. None of these operations fits Ito's original idea of "twinning group": it is to deal with this type of situation that Sadanaga introduced the term "polytypism groupoid". However, one can generate a group from one representative of the partial operations, and the lattice translations $G_{\mathrm{C}}$; the resulting group depends on the choice of the partial operation but its translation sublattice is always a superlattice of the translation sublattice of the polytype: $\mathcal{T}\left(G_{\mathrm{T}}\right) \supset \mathcal{T}\left(G_{\mathrm{C}}\right)$. For example, by taking $\left\{\left.2_{1 \overline{0}}\right|^{2 / 3} \frac{1}{3}^{1 / 2}\right\}$ as generating operation one gets a space group of type $H 121$ (basis vectors in common with $G_{\mathrm{C}}$ ), which is an unconventional setting of $C 121$ to which it is transformed by a change of basis vectors $\mathbf{a}+\mathbf{b},(-\mathbf{a}+\mathbf{b}) / 3, \mathbf{c}$ and an origin shift $0,0,1 / 4$. The same result is obtained 606 607 608 609 610 611 612 613 614 615 616 617 618 619 620 621 
by using one of the other two-fold rotations in the (001), as it should be expected from the fact that

these operations belong to the same conjugacy class in the hexagonal system. If instead the threefold rotations are taken as generators, the result is a group of type $P 3$ with half the period along $c$ with respect to the unit cell of the $2 H$ polytype.

Summarizing, the space groupoid of a modular structure can be classified in two types:

1. the partial operations generate a space group whose translation subgroup coincide with that of the modular structure (Ito's “twinning group”);

2. the partial operations generate a space group whose translation subgroup is a supergroup of that of that of the modular structure (Sadanaga's "polytypism groupoid").

The above dichotomy exhausts the possibilities when the modules (substructures) are layers. However, in case of rods or bricks with non-trivial nuclei, operations corresponding to $q=1$ and operations corresponding to $q>1$ may actually coexist in a mixed group. One concrete example is the case of sepiolite [43], that can be interpreted as composed to rods 8-octahedra thick $\left(\mathrm{Z}_{8}\right.$ modules), in which all the partial operations correspond to $q=1$. However, these rods can be further 635 subdivided into thinner rods 3 -octahedra thick ( $Z_{3}$ modules). In this case the operations mapping $Z_{3}$ modules in different regions of a same or different $\mathrm{Z}_{8}$ modules correspond to $q>1$, whereas operations mapping $\mathrm{Z}_{3}$ modules in the same region of different $\mathrm{Z}_{8}$ modules correspond to $q=1$. The presence of operations corresponding to $q>1$ was excluded by Ito, whose "twinned space groups" 639 are space groupoids in which partial operations correspond to case 1 above. Modular structures in 640 which the modules are related by operations defining Ito's "twinning group" and corresponding to Sadanaga's "polysynthetic structures" have been called "Ito twins" [3]: they represent a special subset of polytypes. Figure 6 provides a revised classification with respect to the scheme proposed by [2]. 


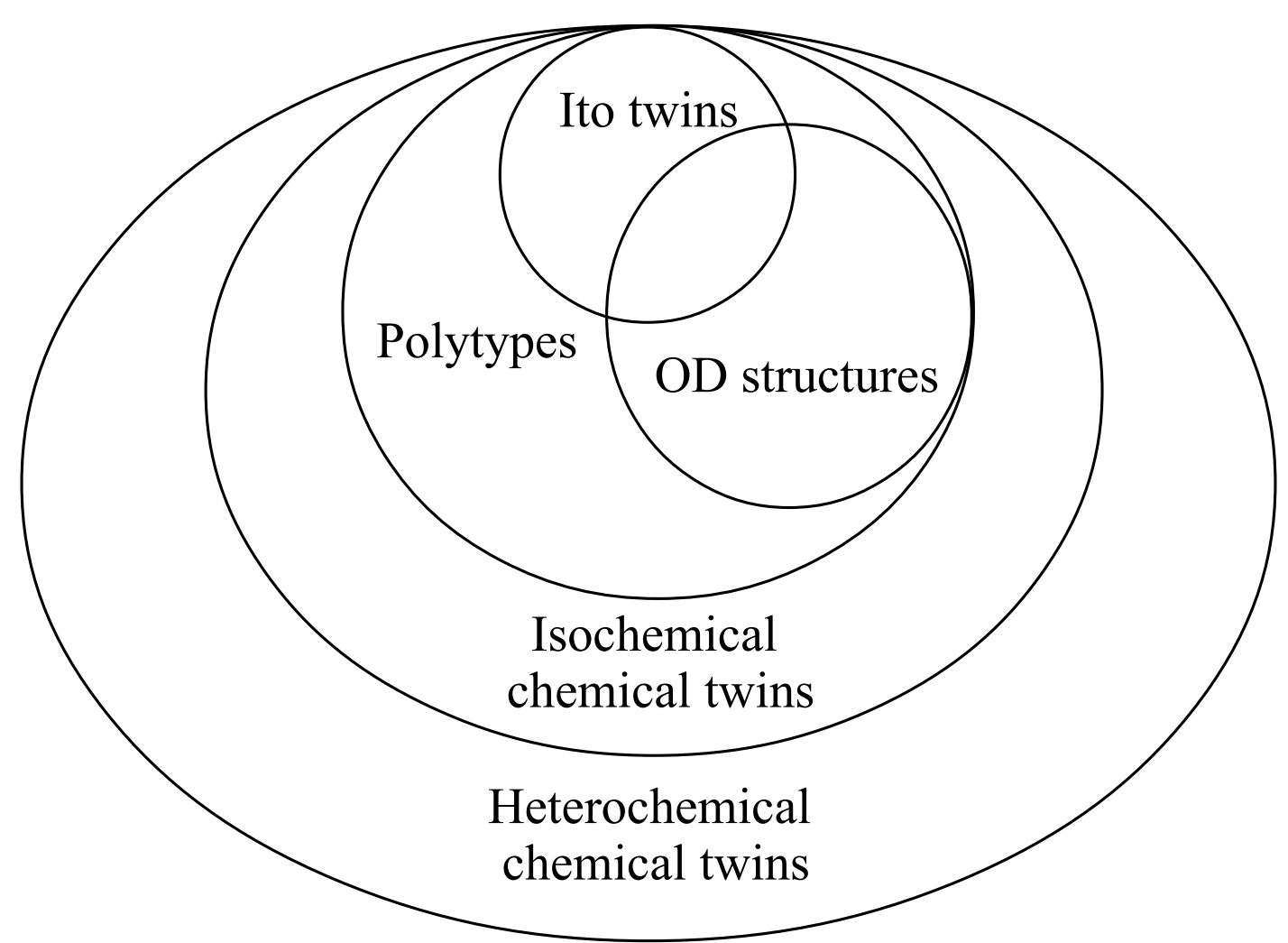

Figure 6: Euler diagram showing a revised classification of monoarchetypal modular structures, or cell-twins. The difference between polytypes and chemical twins consists in the absence or presence, respectively, of "chemical stress" (altered coordination) as the interface between modules. The latter are then classified in heterochemical and isochemical depending on whether the chemical stress does or does not result in a modification of the chemical composition. Concretely, isochemical chemical twins (after [5]) are monoarchetypal modular structures in which at the interface between modules new coordination sites are created but not occupied. Polytypes in which the partial operations mapping the modules are ordinary space-group operations, i.e. for which the group generated by partial operations corresponds to $q=1$ in Eq. (2), are called "Ito twins" (after [3]) and correspond to Ito's and Sadanaga's "polysynthetic structures". OD structures are polytypes in which layer pairs are geometrically equivalent.

\section{Discussion}

A complete analysis of modular crystal structures requires the identification of the space groupoid

which contains the full set of local and partial operations mapping each substructure (module) to

itself and to the other substructures. Ito was the first to realize the need of an algebraic structure

more general than a group to describe the crystal structure of a number minerals that share a common module. Proceeding in an inductive way from the comparison with the well-know 
between substructures in modular structures. His observations suggested that only digonal operations may actually occur; he however included also translation by a half period as a possible structure-building operation. He named "polysynthetic structures" the modular structures he studied, in analogy with the polysynthetic twinning shown by various minerals. Twinning is a macroscopic phenomenon relating the orientation of individuals or domains [8] and may or may not result in multiple individuals; cell-twinning instead acts at the unit-cell level and by definition produces a large number of modules in alternating orientation/position. The choice of the name "polysynthetic structures" seems therefore quite natural. All the modular structures studied by Ito were actually polytypes, or at least "configurational polytypes" [36], because of some deviation in the chemical composition. However, the restriction of partial operation to digonal operations covers only a subset of polytypes, and this subset has been later called "Ito twins" [3], in his name. As we have shown, the translation subgroup defined by the partial operations taken as generators coincide with translation subgroup of the modular structure, which is not the case when the partial operations are not digonal. Assigning this category a special name does therefore make sense and we consider that the term "Ito twins", already present in the literature, should be preserved. On the other hand, the term "twinned space group" is today of only historical interest, being nothing else than a space groupoid, term which is well established in the literature. In the same way, obsolete terms like "twinning group" and "polytypism groupoid" are today a source of confusion and should not be preserved other than for their historical role. Indeed, Ito's “twinning group”, introduced in 1938, in which the partial operations are prolonged to global operations, can be considered the ancestor of the idea of prolonging all the partial and local operations to global operations, introduced much later by the OD school [11], which produces the family structure, a fictitious structure containing all the possible positions and orientation of the substructures (modules). Sadanaga went further in this direction, by removing the restriction to digonal operations, and recognized that this extension results in a wider category. His unfortunate choice of the term "polytype" as exclusive of Ito's 
"polysynthetic structures", as well as the fact that most of his research was published in rare

journals hardly accessible outside Japan, did not help drawing the attention his results actually 680 deserved. With this analysis, we hope to contribute to remediate the oblivion the Japanese research 681 in the field has suffered.

\section{Appendix}

The word "groupoid" has been used in the scientific literature with different meanings.

Hausmann \& Ore [44] defined a groupoid as set on which a binary operation acts, but neither the

The term "groupoid" today is normally used to indicate a small category in which all the morphisms

Brandt groupoids are suitable to describe monoarchetypal modular structures; Ehresmann groupoids 
[1] J.B. Thompson Jr., Am. Mineral. 1978, 63, 239-249. 705

[2] M. Nespolo, G. Ferraris, S Durovič and Y. Takéuchi, Z. Kristallogr. 2004, 219, 773-778. 706

[3] Y. Takéuchi, Tropochemical cell-twinning. A structure building mechanism in crystalline 707 solids. 1997, Tokyo: Terra Scientific. Publishing Company, xiv+319 pp. 708

[4] B.G. Hyde, S. Andersson, M. Bakker, C.M. Plug, and M. O’Keeffe, Progr. Solid State Chem. 709 $\begin{array}{ll}1979,12,185-327 . & 710\end{array}$

[5] S. Andersson, and B,.G. Hyde, J. Sol. State Chem. 1974, 9, 92-101. 711

[6] F. Rinne, Die Kristalle als Vorbilder des feinbaulichen Wesens der Materie. 1921, Berlin: 712 Borntraeger [English translation: Crystals and the fine-structure of matter (translated by 713 Walter S. Stiles). 1922, New York: E.P. Dutton and Co., ix+195 pp]. 714

[7] A.M. Glazer, M.I. Aroyo and A. Authier, Acta Crystallogr. 2014, A70, 300-302. 715

[8] M. Nespolo, Cryst. Res. Techn. 2015, 50, 362-371. 716

[9] R. Sadanaga, Rec. Progr. Nat. Sci. Japan 1978, 3, 143-151. 717

[10] A. Guinier, G.B. Bokij, K, Boll-Dornberger, J.M. Cowlwy, S. Ďurovič, H. Jagodziniski, P. 718 Khrisna, P.M. DeWolff, B.B. Zvyagin, D.E. Cox, P. Goodman, Th. Hahn, K. Kuchitsu and 719 $\begin{array}{ll}\text { S.C. Abrahams, Acta Crystallogr. 1984, 40, 399-404. } & 720\end{array}$

[11] K. Dornberger-Schiff, Grundzüge einer Theorie von OD-Strukturen aus Schichten. Abh 721 dtsch Akad Wiss Berlin, Kl f Chem 1964, 3107 p. 722

[12] K. Fichtner, Beitr. Alg. Geom. 1977, 6, 71-99. 723

[13] B.B. Zvyagin, Phase Trans. 1993, 43, 21-25.

[14] H. Brandt, Math. Ann. 1927, 96, 360-366.

[15] T. Ito, Z. Kristallogr. 1935, 90, 151-162. 726

[16] M. Nespolo and M.I. Aroyo, Eur. J. Mineral. 2016, 28, 189-203. 727

[17] T. Ito, J. Jpn. Assoc. Min. Petr. Econ. Geol. 1938, 20, 201-210 (in Japanese). 728 
[18] T. Ito, X-ray Studies on Polymorphism. Maruzen Co., Tokyo, 1950, 231 pp.

[19] J.D. Dixon, Pac. J. Math. 1963, 13, 73-77. 730

[20] A. Loewy, J. f. Math. 1927, 157, 239-254. 731

[21] R. Sadanaga, J. Min. Soc. Japan 1980, 14, 215-224 (in Japanese). 732

[22] R. Sadanaga, T. Sawada, K. Ohsumi and K. Kamiya, Jpn. Assoc. Min. Petr. Econ. Geol. 733 $\begin{array}{ll}\text { Spec. Issue 1980, 2, 23-29. } & 734\end{array}$

[23] M. Nespolo, Acta Crystallogr. 2019, A75, 551-573. 735

[24] S.W. Bailey, V.A. Frank-Kamenetskii, S. Goldsztaub, A. Kato, A. Pabst, H. Schulz, H.F.W. 736 Taylor, M. Fleischer and A.J.C. Wilson, Acta Crystallogr. 1977, A33, 681-684. 737

[25] G. Giuseppetti, F. Mazzi and C.Tadini, N. Jahrb. Miner. Monats. 1992, 1992, 113-126. 738

[26] C. Friedel, Bull. Soc. fr. Minér. 1894, 17, 6-8. 739

[27] G. Friedel, Bull. Soc. fr. Minér. 1906, 29, 14-55. 740

[28] A. Hadding, Geol. Foren. Stock. For. 1919, 41, 175-192. 741

[29] B. Gossner, and M. Arm, Z. Kristallogr. 1929, 72, 202-236. 742

[30] G. Friedel, Z. Kristallogr., 1930, 73, 147-158. 743

[31] R. Hocart, Z. Kristallogr. 1930, 74, 20-24. 744

[32] Gossner, Z. Kristallogr. 75, 365-366 (1930).

[33] R.C. Rouse, J. Solid St. Chem. 1973, 6, 86-92. 746

[34] M.A. Cooper and F.C. Hawthorne, Can. Mineral. 2000, 38, 801-808. 747

[35] M.I. Aroyo, J.M. Perez-Mato, C. Capillas, E. Kroumova, S. Ivantchev, G. Madariaga, A. 748 Kirov and H. Wondratschek, Z. Kristallogr. 2006, 221, 15-27. 749

[36] G. Ferraris, E. Makovicky and S. Merlino, Crystallography of Modular Materials. Oxford: 750 Oxford University Press 2008, 384 pp..

[37] K. Dornberger-Schiff, Acta Crystallogr. 1959, 12, $173 . \quad 752$ 
[38] V. Kopský and D.B. Litvin, International Tables for Crystallography Volume E: Subperiodic 753 groups. 2010, Hoboken, Wiley, ix+562 pp. $\quad 754$

[39] P. Comodi and P.F. Zanazzi, Am. Miner. 1997, 82, 61-68. 755

[40] T. Armbruster, P. Bonazzi, M. Akasaka, V. Bermanec, C. Chopin, R. Gieré, S. Heuss- 756 Assbichler, A. Liebscher, S. Menchetti, Y. Pan and M. Pasero, Eur. J. Mineral. 2006, 18, 757 $\begin{array}{ll}551-567 . & 758\end{array}$

[40a] S. Durovič, Krist. Techn. 1979, 14, 1047-1053. 759

[41] A. Umayahara and M. Nespolo, Z. Kristallogr. 2018, 233, 179-203. 760

[42] M. Nespolo, A. Umayahara, and J.-G. Eon, Eur. J.Miner., 2018, 30, 413-428. 761

[43] B.A. Hausmann and O. Ore, Am. J. Math. 1937, 59, 983-1004. 762

[44] N. Bourbaki, Elements of Mathematics: Algebra 1. 1998, Berlin, Heidelberg: Springer, 763 $\begin{array}{ll}\text { xxiii+708 pp. } & 764\end{array}$

[45] R.H. Bruck, A Survey of Binary Systems. 1971, Berlin, Heidelberg: Springer, viii+185 pp. 765

[46] E.S. Ljapin and A.E. Evseev The Theory of Partial Algebraic Operations. 1997, Dordrecth: 766 $\begin{array}{ll}\text { Springer, } \mathrm{x}+235 \mathrm{pp} . & 767\end{array}$

[47] W. Taylor, Can. J. Math. 1977, XXIX, 498-527. 768 
Table 1. Comparison of the atomic coordinates of pseudoboleite (left) and of the model of pseudoboleite obtained from the structure of boleite (right), expressed in the maximal common $P 4 / \mathrm{mmm}$ subgroup (hydrogen atoms are not included because of the uncertainty on their position). Atomic pairing is determined by the closest position in the unit cell, ignoring the difference in the chemical nature of the atoms. K in pseudoboleite (Wyckoff position $2 g$ ) as well as all the $\mathrm{Ag}$ are replaced by $\mathrm{Pb}$ in the model obtained from boleite. one pair $\mathrm{O}-\mathrm{Cl}$ is inverted. $\Delta x, \Delta y, \Delta \bar{z}$ are the differences of fractional atomic coordinates, $\mathrm{d}$ is the distance in Ångstroms between the corresponding atoms.

Atom Pairings

WP Atomic coordinates of pseudoboleite

$4 n$

$4 i$

$8 r$

$2 h$

$4 m$

$8 t$

$8 s$

$8 r$

$2 g$

$4 i$

$8 p$

$16 u$

$8 s$

$8 r$

$8 s$

$8 t$

$8 r$

$8 t$

$16 u$

$8 q$

$2 g$

$16 u$

$8 \mathrm{r}$

$16 u$

$8 r$

$\mathrm{Pb}$

$\mathrm{Pb}$

$$
0.7264
$$

$1 / 2$
0.6970

$1 / 2$

0.2264

$1 / 2$

0.7263

0.1970

0

0

0.6698

0.3119

0

0.8120

0.2104

$1 / 2$

0.3120

0.7104

0.8119

0.1698

0

0.0946

0.7443

0.5946

0.2443

$\begin{array}{cc}1 / 2 & 0 \\ 0 & 0.8632 \\ 0.3030 & 0.8485 \\ 1 / 2 & 0.8868 \\ 0 & 1 / 2 \\ 0.7736 & 0.7500 \\ 0 & 0.7500 \\ 0.8030 & 0.3485 \\ 0 & 0.3868 \\ 1 / 2 & 0.3632 \\ 0.2104 & 0 \\ 0.8120 & 0.9060 \\ 0.3302 & 0.8948 \\ 0.1880 & 0.8441 \\ 0 & 0.8349 \\ 0.8302 & 0.3948 \\ 0.6880 & 0.3441 \\ 1 / 2 & 0.3349 \\ 0.3120 & 0.4060 \\ 0.7104 & 1 / 2 \\ 0 & 0.7500 \\ 0.7443 & 0.8722 \\ 0.2557 & 0.9527 \\ 0.2443 & 0.3722 \\ 0.7557 & 0.4527\end{array}$

Atomic coordinates of the pseudoboleite model obtained from boleite

$\begin{array}{cccc}\mathrm{Pb} & 0.7260 & 1 / 2 & 0 \\ \mathrm{~Pb} & 1 / 2 & 0 & 0.8649 \\ \mathrm{~Pb} & 0.6958 & 0.3042 & 0.8490 \\ \mathrm{~Pb} & 1 / 2 & 1 / 2 & 0.8927 \\ \mathrm{~Pb} & 0.2260 & 0 & 1 / 2 \\ \mathrm{~Pb} & 1 / 2 & 0.7750 & 0.7421 \\ \mathrm{~Pb} & 0.7250 & 0 & 0.7579 \\ \mathrm{~Pb} & 0.1958 & 0.8042 & 0.3490 \\ \mathrm{~Pb} & 0 & 0 & 0.3927 \\ \mathrm{~Pb} & 0 & 1 / 2 & 0.3649 \\ \mathrm{O} & 0.6707 & 0.2099 & 0 \\ \mathrm{O} & 0.3118 & 0.8088 & 0.9057 \\ \mathrm{O} & 0 & 0.3306 & 0.8949 \\ \mathrm{O} & 0.8108 & 0.1892 & 0.8460 \\ \mathrm{O} & 0.2108 & 0 & 0.8368 \\ \mathrm{O} & 1 / 2 & 0.8306 & 0.3949 \\ \mathrm{O} & 0.3108 & 0.6892 & 0.3460 \\ \mathrm{O} & 0.7108 & 1 / 2 & 0.3368 \\ \mathrm{O} & 0.8118 & 0.3088 & 0.4057 \\ \mathrm{O} & 0.1707 & 0.7099 & 1 / 2 \\ \mathrm{~Pb} & 0 & 0 & 0.7284 \\ \mathrm{Cu} & 0.0953 & 0.7434 & 0.8733 \\ \mathrm{Cu} & 0.7435 & 0.2565 & 0.9529 \\ \mathrm{Cu} & 0.5953 & 0.2434 & 0.3733 \\ \mathrm{Cu} & 0.2435 & 0.7565 & 0.4529\end{array}$

$\begin{array}{cccc}\Delta \boldsymbol{x} & \Delta \boldsymbol{y} & \boldsymbol{\Delta} \boldsymbol{z} & \mathbf{d}(\mathbf{\AA}) \\ -0.0004 & 0.0000 & 0.0000 & 0.0067 \\ 0.0000 & 0.0000 & 0.0017 & 0.0514 \\ -0.0012 & 0.0012 & 0.0005 & 0.0301 \\ 0.0000 & 0.0000 & 0.0059 & 0.1795 \\ -0.0004 & 0.0000 & 0.0000 & 0.0067 \\ 0.0000 & 0.0014 & -0.0079 & 0.2426 \\ -0.0013 & 0.0000 & 0.0079 & 0.2424 \\ -0.0012 & 0.0012 & 0.0005 & 0.0301 \\ 0.0000 & 0.0000 & 0.0059 & 0.1795 \\ 0.0000 & 0.0000 & 0.0017 & 0.0514 \\ 0.0009 & -0.0005 & 0.0000 & 0.0157 \\ -0.0001 & -0.0032 & -0.0003 & 0.0498 \\ 0.0000 & 0.0004 & 0.0001 & 0.0068 \\ -0.0012 & 0.0012 & 0.0019 & 0.0650 \\ 0.0004 & 0.0000 & 0.0019 & 0.0584 \\ 0.0000 & 0.0004 & 0.0001 & 0.0068 \\ -0.0012 & 0.0012 & 0.0019 & 0.0650 \\ 0.0004 & 0.0000 & 0.0019 & 0.0584 \\ -0.0001 & -0.0032 & -0.0003 & 0.0498 \\ 0.0009 & -0.0005 & 0.0000 & 0.0157 \\ 0.0000 & 0.0000 & -0.0216 & 0.6604 \\ 0.0007 & -0.0009 & 0.0011 & 0.0389 \\ -0.0008 & 0.0008 & 0.0002 & 0.0189 \\ 0.0007 & -0.0009 & 0.0011 & 0.0389 \\ -0.0008 & 0.0008 & 0.0002 & 0.0189\end{array}$




\begin{tabular}{|c|c|c|c|c|c|c|c|c|c|c|c|c|}
\hline $4 l$ & $\mathrm{O}$ & 0 & 0.3296 & 0 & $\mathrm{Cl}$ & 0 & 0.3265 & 0.0000 & 0.0000 & -0.0031 & 0.0000 & 0.0474 \\
\hline $8 t$ & $\mathrm{Cl}$ & 0.8684 & $1 / 2$ & 0.9342 & $\mathrm{Cl}$ & 0.8704 & $1 / 2$ & 0.9341 & 0.0020 & 0.0000 & -0.0001 & 0.0307 \\
\hline $8 r$ & $\mathrm{Cl}$ & 0.8778 & 0.1222 & 0.9389 & $\mathrm{Cl}$ & 0.8780 & 0.1220 & 0.9383 & 0.0002 & -0.0002 & -0.0006 & 0.0188 \\
\hline $8 r$ & $\mathrm{Cl}$ & 0.6152 & 0.3848 & 0.9395 & $\mathrm{Cl}$ & 0.6163 & 0.3837 & 0.9408 & 0.0011 & -0.0011 & 0.0013 & 0.0463 \\
\hline $2 g$ & $\mathrm{Cl}$ & 0 & 0 & 0.8352 & $\mathrm{Cl}$ & 0 & 0 & 0.8261 & 0.0000 & 0.0000 & -0.0091 & 0.2782 \\
\hline $16 u$ & $\mathrm{Cl}$ & 0.1210 & 0.6152 & 0.8076 & $\mathrm{Cl}$ & 0.1219 & 0.6161 & 0.8076 & 0.0009 & 0.0009 & 0.0000 & 0.0195 \\
\hline $8 t$ & $\mathrm{Cl}$ & 0.6694 & $1 / 2$ & 0.8347 & $\mathrm{Cl}$ & 0.6736 & $1 / 2$ & 0.8402 & 0.0042 & 0.0000 & 0.0055 & 0.1800 \\
\hline $16 u$ & $\mathrm{Cl}$ & 0.6210 & 0.1152 & 0.3076 & $\mathrm{Cl}$ & 0.6219 & 0.1161 & 0.3076 & 0.0009 & 0.0009 & 0.0000 & 0.0195 \\
\hline $8 s$ & $\mathrm{Cl}$ & 0.3684 & 0 & 0.4342 & $\mathrm{Cl}$ & 0.3704 & 0 & 0.4341 & 0.0020 & 0.0000 & -0.0001 & 0.0307 \\
\hline $2 h$ & $\mathrm{Cl}$ & $1 / 2$ & $1 / 2$ & 0.3352 & $\mathrm{Cl}$ & $1 / 2$ & $1 / 2$ & 0.3261 & 0.0000 & 0.0000 & -0.0091 & 0.2782 \\
\hline $8 s$ & $\mathrm{Cl}$ & 0.1694 & 0 & 0.3347 & $\mathrm{Cl}$ & 0.1736 & 0 & 0.3402 & 0.0042 & 0.0000 & 0.0055 & 0.1800 \\
\hline $8 r$ & $\mathrm{Cl}$ & 0.8306 & 0.8306 & 0.7500 & $\mathrm{Cl}$ & 0.8579 & 0.8579 & 0.7512 & 0.0273 & 0.0273 & 0.0012 & 0.5914 \\
\hline $8 r$ & $\mathrm{Cl}$ & 0.6316 & 0.6316 & 0.7500 & $\mathrm{Cl}$ & 0.6421 & 0.6421 & 0.7488 & 0.0105 & 0.0105 & -0.0012 & 0.2300 \\
\hline $4 o$ & $\mathrm{Cl}$ & $1 / 2$ & 0.8296 & $1 / 2$ & $\mathrm{Cl}$ & $1 / 2$ & 0.8265 & $1 / 2$ & 0.0000 & -0.0031 & 0.0000 & 0.0474 \\
\hline $8 r$ & $\mathrm{Cl}$ & 0.1152 & 0.8848 & 0.4395 & $\mathrm{Cl}$ & 0.1163 & 0.8837 & 0.4408 & 0.0011 & -0.0011 & 0.0013 & 0.0463 \\
\hline $8 r$ & $\mathrm{Cl}$ & 0.3778 & 0.6222 & 0.4389 & $\mathrm{Cl}$ & 0.3780 & 0.6220 & 0.4383 & 0.0002 & -0.0002 & -0.0006 & 0.0188 \\
\hline $4 l$ & $\mathrm{Ag}$ & 0 & 0.1573 & 0 & $\mathrm{~Pb}$ & 0 & 0.1547 & 0 & 0.0000 & -0.0026 & 0.0000 & 0.0397 \\
\hline $2 f$ & $\mathrm{Ag}$ & 0 & $1 / 2$ & 0 & $\mathrm{~Pb}$ & 0 & $1 / 2$ & 0 & 0.0000 & 0.0000 & 0.0000 & 0.0000 \\
\hline $2 g$ & $\mathrm{Ag}$ & 0 & 0 & 0.9214 & $\mathrm{~Pb}$ & 0 & 0 & 0.9163 & 0.0000 & 0.0000 & -0.0050 & 0.1544 \\
\hline $2 e$ & $\mathrm{Ag}$ & $1 / 2$ & 0 & $1 / 2$ & $\mathrm{~Pb}$ & $1 / 2$ & 0 & $1 / 2$ & 0.0000 & 0.0000 & 0.0000 & 0.0000 \\
\hline $4 o$ & $\mathrm{Ag}$ & $1 / 2$ & 0.6573 & $1 / 2$ & $\mathrm{~Pb}$ & $1 / 2$ & 0.6547 & $1 / 2$ & 0.0000 & -0.0026 & 0.0000 & 0.0397 \\
\hline $2 h$ & $\mathrm{Ag}$ & $1 / 2$ & $1 / 2$ & 0.4214 & $\mathrm{~Pb}$ & $1 / 2$ & $1 / 2$ & 0.4163 & 0.0000 & 0.0000 & -0.0050 & 0.1544 \\
\hline $2 h$ & $\mathrm{Ag}$ & $1 / 2$ & $1 / 2$ & 0.7500 & $\mathrm{~Pb}$ & $1 / 2$ & $1 / 2$ & 0.7716 & 0.0000 & 0.0000 & 0.0216 & 0.6604 \\
\hline
\end{tabular}

Table 2. The space groupoid of pseudoboleite obtained by applying the partial operation $\mathrm{t}\left(\overline{1 / 2} \frac{1 / 21 / 2}{2}\right)$ to the nucleus $P(4 / \mathrm{m}) \mathrm{mm}$ expressing the diperiodic symmetry of layer common to boleite and pseudoboleite.

\begin{tabular}{|c|c|}
\hline$P(4 / m) m m$ & $P(4 / m) m m t(\overline{1 / 21 / 21 / 2})$ \\
\hline$\{1 \mid 000\}$ & $\{t \mid \overline{1 / 21 / 21 / 2}\}$ \\
\hline$\left\{2_{001} \mid 000\right\}$ & $\left\{\left.2_{001}\right|^{\overline{1 / 2} 2^{1 / 21 / 2}}\right\}$ \\
\hline$\left\{4^{+} 001 \mid 000\right\}$ & $\left\{4^{+}{ }_{001} \overline{1 / 21 / 21 / 2}\right\}$ \\
\hline$\left\{4^{-} 001 \mid 000\right\}$ & $\left\{4_{001}^{-} \overline{1 / 21 / 21 / 2}\right\}$ \\
\hline
\end{tabular}




\begin{tabular}{|c|c|}
\hline$\left\{2_{010} \mid 000\right\}$ & $\left\{2_{010} \overline{1 / 21 / 21 / 2}\right\}$ \\
\hline$\left\{2_{100} \mid 000\right\}$ & $\left\{\left.2_{100}\right|^{1 / 21 / 21 / 2}\right\}$ \\
\hline$\left\{2_{110} \mid 000\right\}$ & $\left\{2_{110} \mid \frac{1 / 21 / 21 / 2}{1}\right\}$ \\
\hline$\left\{2_{1 \overline{1} 0} \mid 000\right\}$ & $\left\{\left.2_{1 \overline{1} 0}\right|^{1 / 21 / 21 / 2}\right\}$ \\
\hline$\{\overline{1} \mid 000\}$ & $\left\{\left.\overline{1}\right|^{1 / 21 / 21 / 2}\right\}$ \\
\hline$\left\{m_{001} \mid 000\right\}$ & $\left\{\left.m_{001}\right|^{1 / 2} 2^{1 / 2} 1 / 2\right\}$ \\
\hline$\left\{\overline{4}^{+}{ }_{001} \mid 000\right\}$ & $\left\{\left.\overline{4}^{+}{ }_{001}\right|^{1 / 21 / 21 / 2}\right\}$ \\
\hline$\left\{\overline{4}_{001} \mid 000\right\}$ & $\left\{\overline{4}_{001}^{-1 / 21 / 21 / 2}\right\}$ \\
\hline$\left\{m_{010} \mid 000\right\}$ & $\left\{\left.m_{010}\right|^{1 / 2} 2^{1 / 2} 1 / 2\right\}$ \\
\hline$\left\{m_{100} \mid 000\right\}$ & $\left\{\left.m_{100}\right|^{1 / 2} 2^{1 / 2} 1 / 2\right\}$ \\
\hline$\left\{m_{110} \mid 000\right\}$ & $\left\{\left.m_{110}\right|^{1 / 21 / 21 / 2}\right\}$ \\
\hline$\left\{m_{1 \overline{1}} \mid 000\right\}$ & $\left\{m_{1 \overline{1} 0} \mid \frac{1 / 21 / 21 / 2}{1}\right\}$ \\
\hline$t(1 / 21 / 21 / 2) P(4 / m) m m$ & 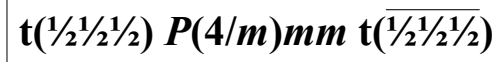 \\
\hline$\{t \mid 1 / 21 / 21 / 2\}$ & $\{1 \mid 0\}$ \\
\hline$\left\{\left.2_{001}\right|^{1 / 21 / 2} 1 / 2\right\}$ & $\left\{2_{001} \mid \overline{11} 0\right\}$ \\
\hline$\left\{\left.4^{+}{ }_{001}\right|^{1 / 2} \frac{1}{2} 2^{1} / 2\right\}$ & $\left\{4^{+}{ }_{001} \mid \overline{1} 00\right\}$ \\
\hline$\left\{\left.4_{001}^{-}\right|^{1 / 2} \overline{1} / 21 / 2\right\}$ & $\left\{4_{001}^{-} \mid 0 \overline{1} 0\right\}$ \\
\hline$\left\{\left.2_{010}\right|^{\overline{1} / 2} \frac{1}{1 / 2} \overline{2}\right\}$ & $\left\{2_{010} \mid \overline{1} 0 \overline{1}\right\}$ \\
\hline$\left\{\left.2_{100}\right|^{1 / 2} \overline{2^{1 / 2} 1 / 2}\right\}$ & $\left\{2_{100} \mid 0 \overline{11}\right\}$ \\
\hline$\left\{\left.2_{110}\right|^{1 / 2} 1 / 2 \overline{1} / 2\right\}$ & $\left\{2_{110} \mid 00 \overline{1}\right\}$ \\
\hline$\left\{2_{11} \mid \overline{1 / 21 / 21 / 2}\right\}$ & $\left\{2_{1 \overline{1} 0} \mid \overline{111}\right\}$ \\
\hline$\{\overline{1} \mid \overline{1 / 21 / 21 / 2}\}$ & $\{\overline{1} \mid \overline{111}\}$ \\
\hline$\left\{\left.m_{001}\right|^{1} / 21 / 2 \overline{2} 1 / 2\right\}$ & $\left\{m_{001} \mid 00 \overline{1}\right\}$ \\
\hline$\left\{\overline{4}^{+}{ }_{001} \mid 1 \frac{1}{1 / 2} \frac{1}{1 / 2}\right\}$ & $\left\{\overline{4}^{+}{ }_{001} \mid 0 \overline{11}\right\}$ \\
\hline
\end{tabular}




\begin{tabular}{|c|c|}
\hline$\left\{\left.\overline{4}_{001}\right|^{1 / 2} 1 / 2 \overline{2} \frac{\overline{1}}{2}\right\}$ & $\left\{\overline{4}_{001}^{-} \mid \overline{1} 0 \overline{1}\right\}$ \\
\hline$\left\{\left.m_{010}\right|^{1 / 2} \overline{1}^{1 / 2} 1 / 2\right\}$ & $\left\{m_{010} \mid 0 \overline{1} 0\right\}$ \\
\hline$\left\{\left.m_{100}\right|^{1 / 2} 2^{1 / 2} 1 / 2\right\}$ & $\left\{m_{100} \mid \overline{1} 00\right\}$ \\
\hline$\left\{\left.m_{110}\right|^{1 / 21 / 2} 1 / 2\right\}$ & $\left\{m_{110} \mid \overline{11} 0\right\}$ \\
\hline$\left\{m_{1 \overline{1} 0} \mid 1 / 21 / 21 / 2\right\}$ & $\left\{m_{1 \overline{1} 0} \mid 000\right\}$ \\
\hline
\end{tabular}

Table 3. Comparison of the atomic coordinates of zoisite (right) and of the model of zoisite obtained from the structure of clinozoisite (left), expressed in the maximal common $P 12_{1} 1 / m$ subgroup (hydrogen atoms are not included because of the uncertainty on their position). Same conventions as in Table 1.

$\mathbf{W P}$
$2 e$
$4 f$
$2 e$
$4 f$
$2 e$
$2 e$
$2 e$
$2 e$
$2 e$
$2 e$
$2 e$
$4 f$
$4 f$
$2 e$
$2 e$
$2 e$
$2 e$
$2 e$
$4 f$

\section{Atomic coordinates of the model of zoisite obtained}

\section{Atom Pairings}

\section{from clilnozoisite}

0.6054
0.7500
0.8947
0.7500
0.0534
0.1303
0.3697
0.4466
0.0084
0.0061
0.0692
0.1447
0.3554
0.4308
0.4917
0.4939
0.7115
0.7229
0.6328

$$
\begin{aligned}
& 3 / 4 \\
& 0.0000
\end{aligned}
$$$$
0.1708
$$$$
\text { Al } \quad 0.7500
$$$$
\mathrm{Al} \quad 0.8947
$$$$
\mathrm{Al} \quad 0.7500
$$$$
\mathrm{Ca}
$$$$
\mathrm{Ca}
$$$$
\mathrm{Ca}
$$$$
\mathrm{Ca}
$$$$
\mathrm{O}
$$$$
\mathrm{O}
$$$$
\mathrm{O}
$$$$
\mathrm{O}
$$$$
\mathrm{O}
$$$$
\mathrm{O}
$$$$
\mathrm{O}
$$$$
\mathrm{O}
$$$$
\mathrm{O}
$$$$
\mathrm{O}
$$$$
\mathrm{O}
$$

\section{Atomic coordinates of zoisite}

0.6055
0.7497
0.8945
0.7503
0.0482
0.1332
0.3668
0.4518
0.0084
0.0040
0.0789
0.1413
0.3587
0.4211
0.4916
0.4960
0.7318
0.7193
0.6307

\section{Atomic Displacements}

\section{$\Delta x \quad \Delta y \quad \Delta z \quad \mathrm{~d}(\AA)$}

$\begin{array}{lllllll}3 / 4 & 0.1996 & 0.0001 & 0.0000 & 0.0289 & 0.2930\end{array}$ $\begin{array}{lllllll}0.9970 & 0.3103 & -0.0003 & -0.0030 & 0.0603 & 0.6112\end{array}$

$\begin{array}{lllllll}1 / 4 & 0.6996 & -0.0001 & 0.0000 & 0.0289 & 0.2923\end{array}$

$\begin{array}{lllllll}0.0030 & 0.8103 & 0.0003 & 0.0030 & 0.0603 & 0.6127\end{array}$

$\begin{array}{lllllll}3 / 4 & 0.6150 & -0.0052 & 0.0000 & -0.0149 & 0.1842\end{array}$

$\begin{array}{lllllll}3 / 4 & 0.9373 & 0.0029 & 0.0000 & -0.0384 & 0.3850\end{array}$

$\begin{array}{lllllll}1 / 4 & 0.4373 & -0.0029 & 0.0000 & -0.0384 & 0.3996\end{array}$

$\begin{array}{lllllll}1 / 4 & 0.1150 & 0.0052 & 0.0000 & -0.0149 & 0.1612\end{array}$

$\begin{array}{lllllll}3 / 4 & 0.8361 & 0.0001 & 0.0000 & 0.0060 & 0.0605\end{array}$

$\begin{array}{lllllll}1 / 4 & 0.7048 & -0.0021 & 0.0000 & -0.0037 & 0.0545\end{array}$

$\begin{array}{lllllll}1 / 4 & 0.9431 & 0.0097 & 0.0000 & -0.0228 & 0.2586\end{array}$

$\begin{array}{llllll}0.0103 & 0.7450 & -0.0034 & -0.0026 & -0.0542 & 0.5616\end{array}$

$\begin{array}{lllllll}0.5103 & 0.2450 & 0.0034 & -0.0026 & -0.0542 & 0.5447\end{array}$

$\begin{array}{lllllll}3 / 4 & 0.4431 & -0.0097 & 0.0000 & -0.0228 & 0.2994\end{array}$

$\begin{array}{lllllll}1 / 4 & 0.3361 & -0.0001 & 0.0000 & 0.0060 & 0.0602\end{array}$

$\begin{array}{lllllll}3 / 4 & 0.2048 & 0.0021 & 0.0000 & -0.0037 & 0.0466\end{array}$

$\begin{array}{lllllll}3 / 4 & 0.9246 & 0.0203 & 0.0000 & 0.0607 & 0.7423\end{array}$

$\begin{array}{lllllll}3 / 4 & 0.1996 & -0.0036 & 0.0000 & 0.0541 & 0.5423\end{array}$

$\begin{array}{lllllll}0.5006 & 0.3547 & -0.0021 & 0.0042 & 0.0321 & 0.3229\end{array}$ 


$\begin{array}{lllllllllllll}4 f & \mathrm{O} & 0.5995 & 0.4852 & 0.0484 & \mathrm{O} & 0.6011 & 0.4863 & 0.0691 & 0.0016 & 0.0011 & 0.0208 & 0.2164 \\ 2 e & \mathrm{O} & 0.7195 & 1 / 4 & 0.8790 & \mathrm{O} & 0.7282 & 1 / 4 & 0.9400 & 0.0087 & 0.0000 & 0.0610 & 0.6558 \\ 2 e & \mathrm{O} & 0.7885 & 1 / 4 & 0.3639 & \mathrm{O} & 0.7682 & 1 / 4 & 0.4246 & -0.0203 & 0.0000 & 0.0607 & 0.6513 \\ 2 e & \mathrm{O} & 0.7805 & 3 / 4 & 0.3790 & \mathrm{O} & 0.7718 & 3 / 4 & 0.4400 & -0.0087 & 0.0000 & 0.0610 & 0.6128 \\ 2 e & \mathrm{O} & 0.7302 & 1 / 4 & 0.1266 & \mathrm{O} & 0.7275 & 1 / 4 & 0.1881 & -0.0027 & 0.0000 & 0.0615 & 0.6185 \\ 4 f & \mathrm{O} & 0.9006 & 0.9852 & 0.5484 & \mathrm{O} & 0.8989 & 0.9863 & 0.5691 & -0.0016 & 0.0011 & 0.0208 & 0.2081 \\ 2 e & \mathrm{O} & 0.7772 & 1 / 4 & 0.6456 & \mathrm{O} & 0.7807 & 1 / 4 & 0.6996 & 0.0036 & 0.0000 & 0.0541 & 0.5602 \\ 4 f & \mathrm{O} & 0.8672 & 0.9964 & 0.8226 & \mathrm{O} & 0.8693 & 0.0006 & 0.8547 & 0.0021 & 0.0042 & 0.0321 & 0.3335 \\ 2 e & \mathrm{O} & 0.7698 & 3 / 4 & 0.6266 & \mathrm{O} & 0.7725 & 3 / 4 & 0.6881 & 0.0027 & 0.0000 & 0.0615 & 0.6322 \\ 2 e & \mathrm{Si} & 0.0896 & 1 / 4 & 0.8144 & \mathrm{Si} & 0.0895 & 1 / 4 & 0.7824 & -0.0001 & 0.0000 & -0.0319 & 0.3242 \\ 2 e & \mathrm{Si} & 0.5808 & 1 / 4 & 0.3712 & \mathrm{Si} & 0.5813 & 1 / 4 & 0.3945 & 0.0006 & 0.0000 & 0.0233 & 0.2384 \\ 2 e & \mathrm{Si} & 0.4105 & 3 / 4 & 0.3144 & \mathrm{Si} & 0.4105 & 3 / 4 & 0.2824 & 0.0001 & 0.0000 & -0.0319 & 0.3240 \\ 2 e & \mathrm{Si} & 0.6587 & 1 / 4 & 0.0249 & \mathrm{Si} & 0.6600 & 1 / 4 & 0.0643 & 0.0013 & 0.0000 & 0.0394 & 0.4035 \\ 2 e & \mathrm{Si} & 0.9193 & 3 / 4 & 0.8712 & \mathrm{Si} & 0.9187 & 3 / 4 & 0.8945 & -0.0006 & 0.0000 & 0.0233 & 0.2356 \\ 2 e & \mathrm{Si} & 0.8413 & 3 / 4 & 0.5249 & \mathrm{Si} & 0.8400 & 3 / 4 & 0.5643 & -0.0013 & 0.0000 & 0.0394 & 0.3969\end{array}$

Table 4. The space groupoid of zoisite obtained by applying the partial operation $\left\{m_{100} \mid \frac{1 / 2}{1 / 21 / 2}\right\}$ to the nucleus $P(1) 2_{1} / m 1$ expressing the diperiodic symmetry of layer common to clinozoisite and zoisite.

\begin{tabular}{|c|c|}
\hline$P(1) 2_{1} / m 1$ & $P(1) 2_{1} / m 1\left\{m_{100} \mid \frac{1 / 2}{1 / 21 / 2}\right\}$ \\
\hline$\{1 \mid 000\}$ & $\left\{\left.m_{100}\right|^{1 / 2} \overline{1 / 2} \frac{1}{1 / 2}\right\}$ \\
\hline$\left\{2_{010} \mid 0^{1 / 2} / 2\right\}$ & $\left\{m_{001} \mid \overline{1 / 2} 0^{\overline{1} / 2}\right\}$ \\
\hline$\{\overline{1} \mid 000\}$ & $\left\{\left.2_{100}\right|^{\overline{1} / 2} 1 / 21 / 2\right\}$ \\
\hline$\left\{m_{010} \mid 01 / 20\right\}$ & $\left\{2_{001} \mid \frac{1}{1 / 2} 1_{1 / 2}\right\}$ \\
\hline$\left\{\left.m_{100}\right|^{1 / 21 / 2} \frac{1}{2}\right\} P(1) 2_{1} / m 1$ & $\left\{m_{100} \mid 1 \frac{1}{1} 2^{1 / 2}\right\} P(1) 2_{1} / m 1\left\{\left.m_{100}\right|^{1 / 21 / 21 / 2}\right\}$ \\
\hline$\left\{\left.m_{100}\right|^{1 / 2} 2^{1 / 2} 2^{1} / 2\right\}$ & $\{1 \mid 000\}$ \\
\hline$\left\{\left.m_{001}\right|^{1 / 2} 1^{1 / 2}\right\}$ & $\left\{2_{010} \mid 1 \frac{1}{2} 1\right\}$ \\
\hline$\left\{\left.2_{100}\right|^{1 / 2} 2^{1 / 2} 1 / 2\right\}$ & $\{\overline{1} \mid 111\}$ \\
\hline$\left\{\left.2_{001}\right|^{1 / 2} 1^{1 / 2}\right\}$ & $\left\{m_{010} \mid 03 / 20\right\}$ \\
\hline
\end{tabular}


Table 5. The local operations in the nucleus $N_{B}$ of the layer $B$ the of $A B(2 H)$ polytype obtained by conjugation $t(2 / 31 / 31 / 2) N_{A} t\left(\frac{2 / 3}{1 / 3} 3^{1 / 2}\right)$ of nucleus of the $A$ layer. In bold the operations that differ by a full lattice translation and have a continuation from one layer to other, being therefore prolonged to global operations of the polytype. The infinitely many operations of $\mathrm{N}_{\mathrm{A}}$ are represented by the 24 operations with a reduced translational component (zero in this case). The operations are represented by their Seitz symbol.

\begin{tabular}{|c|c|c|c|}
\hline No. & Operation & No. & Operation \\
\hline 1 & $t\left(2 / 3^{1 / 3} 3^{1 / 2}\right)\{1 \mid 000\} t\left(\overline{\left(2 / 3^{1 / 3} / 1 / 2\right.}\right)=\{1 \mid 000\}$ & 13 & 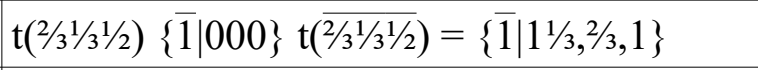 \\
\hline 2 & 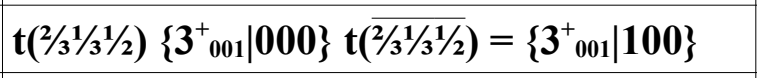 & 14 & $\mathrm{t}\left(\mathrm{2}^{2 / 3} \mathrm{3}^{1 / 1 / 2}\right)\left\{\overline{3}^{+}{ }_{001} \mid 000\right\} \mathrm{t}\left(\overline{\overline{2}^{1 / 3} 3^{1 / 2}}\right)=\left\{\left.\overline{3}^{+}{ }_{001}\right|^{1 / 3} \mathbf{3}^{2 / 3} 1\right\}$ \\
\hline 3 & $\mathbf{t}\left(\mathrm{2}^{1 / 3^{1 / 3} / 2}\right)\left\{3^{-}{ }_{001} \mid 000\right\} \mathbf{t}(\overline{2 / 3 / 3 / 3 / 2})=\left\{3^{-}-110\right\}$ & 15 & $\mathrm{t}\left(2^{2 / 3} 1 / 3^{1} / 2\right)\left\{\overline{3}_{001}^{-} \mid 000\right\} \mathrm{t}\left(\overline{2}^{2 / 3^{1 / 3} / 2}\right)=\left\{\left.\overline{3}_{001}^{-}\right|^{1 / 3} \overline{1 / 3} 1\right\}$ \\
\hline 4 & 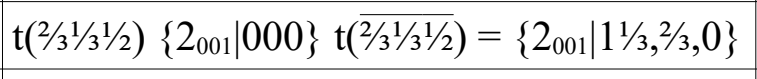 & 16 & $\mathbf{t}(2 / 31 / 31 / 2)\left\{m_{001} \mid 000\right\} t(\overline{2 / 3 / 3 / 3 / 2})=\left\{m_{001} \mid 001\right\}$ \\
\hline 5 & $\mathrm{t}\left(2^{2 / 3} 1 / 3^{1 / 2}\right)\left\{6_{001}^{-} \mid 000\right\} \mathrm{t}\left(\overline{\left(2 / 3^{1 / 3} / 2 / 2\right.}\right)=\left\{\left.6_{001}^{-1 / 3}\right|^{2 / 30}\right\}$ & 17 & $t\left(2 / 31 / 33^{1 / 2)}\left\{\overline{6}_{001}^{-} \mid 000\right\} t\left(\overline{(2 / 3 / 3}^{1 / 1 / 2}\right)=\left\{\overline{6}_{001}^{-} \mid 101\right\}\right.$ \\
\hline 6 & $\mathrm{t}\left(2 / 3^{1 / 3} 3^{1 / 2}\right)\left\{6^{+}{ }_{001} \mid 000\right\} \mathrm{t}\left(\overline{2 / 3^{1 / 3} / 2}\right)=\left\{\left.6^{+}{ }_{001}\right|^{1 / 3} \overline{1 / 3} 0\right\}$ & 18 & $\mathbf{t}\left(2 / 3^{1} 1 / 3^{1 / 2}\right)\left\{\overline{6}^{+}{ }_{001} \mid 000\right\} \mathbf{t}\left(\overline{2 / 33^{1} / 3^{1 / 2}}\right)=\left\{\overline{6}^{+}{ }_{001} \mid 111\right\}$ \\
\hline 7 & $\mathrm{t}\left(2^{2 / 3} 3^{1 / 3} 1 / 2\right)\left\{2_{110} \mid 000\right\} \mathrm{t}\left(\overline{2 / 3^{1 / 3} / 2}\right)=\left\{\left.2_{110}\right|^{1 / 3} \overline{1 / 3} 1\right\}$ & 19 & $\mathbf{t}\left(2^{2} / 3^{1 / 3} \mathbf{3}^{1 / 2}\right)\left\{m_{110} \mid 000\right\} \mathbf{t}\left(\overline{2 / 3} \mathbf{3}^{1 / 3 / 2}\right)=\left\{m_{110} \mid 110\right\}$ \\
\hline 8 & $\mathrm{t}\left(2^{2 / 3} 1 / 3^{1 / 2}\right)\left\{2_{100} \mid 000\right\} \mathrm{t}\left(\overline{2 / 3} 1 / 3^{1 / 2}\right)=\left\{\left.2_{100}\right|^{1 / 3} 3^{2 / 3} 1\right\}$ & 20 & $t(2 / 31 / 31 / 2)\left\{m_{100} \mid 000\right\} t(\overline{2 / 3 / 3 / 3 / 2})=\left\{m_{100} \mid 100\right\}$ \\
\hline 9 & $\mathrm{t}\left(2 / 3^{1 / 3} 3^{1 / 2}\right)\left\{2_{010} \mid 000\right\} \mathrm{t}\left(\overline{2 / 3^{1} / 3^{1 / 2}}\right)=\left\{2_{010} \mid 1 \frac{1 / 3}{3}, 2 / 3,1\right\}$ & 21 & $\mathbf{t}\left(2 / 3^{1 / 3} 3^{1 / 2}\right)\left\{m_{010} \mid 000\right\} \mathbf{t}(\overline{2 / 3 / 3 / 3 / 2})=\left\{m_{010} \mid 000\right\}$ \\
\hline 10 & $t\left(2 / 3^{1 / 3} 3^{1 / 2}\right)\left\{2_{1 \overline{1} 0} \mid 000\right\} t(\overline{2 / 3 / 3 / 3 / 2})=\left\{2_{1 \overline{1} 0} \mid 111\right\}$ & 22 & $\mathrm{t}\left(2 / 3^{1 / 3} 3^{1 / 2}\right)\left\{m_{1 \overline{1} 0} \mid 000\right\} \mathrm{t}\left(\overline{2 / 3} 3^{1 / 3 / 2}\right)=\left\{\left.m_{1 \overline{1} 0}\right|^{1 / 3} \overline{1 / 3} 0\right\}$ \\
\hline 11 & $t\left(2 / 3^{1 / 3} 1 / 2\right)\left\{2_{120} \mid 000\right\} t(\overline{2 / 3 / 3 / 31 / 2})=\left\{2_{120} \mid 101\right\}$ & 23 & $\mathrm{t}\left(2^{2 / 3} 1 / 31 / 2\right)\left\{m_{120} \mid 000\right\} \mathrm{t}(\overline{2 / 31 / 3 / 2})=\left\{\left.m_{120}\right|^{1 / 3}{ }^{2 / 3} 0\right\}$ \\
\hline 12 & $t\left(2 / 3^{1 / 3} 1 / 2\right)\left\{2_{210} \mid 000\right\} t(\overline{2 / 3 / 3 / 31 / 2})=\left\{2_{210} \mid 001\right\}$ & 24 & $\mathrm{t}\left(2^{2} 3^{1 / 3} 1 / 2\right)\left\{m_{210} \mid 000\right\} \mathrm{t}\left(\overline{2 / 3^{1 / 3} / 1 / 2}\right)=\left\{m_{210} \mid 1 \frac{1 / 3}{3}, 2 / 3,0\right\}$ \\
\hline
\end{tabular}


Table 6. The partial operations of the groupoid of the AB polytype that are prolonged to global operations. This occurs when the operations $\Phi(\mathrm{B} \rightarrow \mathrm{A})$ and $\Phi(\mathrm{A} \rightarrow \mathrm{B})$ differ by a full lattice translation. The infinitely many operations of are represented by the 12 operations with a reduced translational component. The operations are represented by their Seitz symbol.

\begin{tabular}{|c|c|c|c|}
\hline & \multirow{3}{*}{\begin{tabular}{|l|} 
First row of $\mathscr{D}: \Phi(\mathrm{B} \rightarrow \mathrm{A})$ \\
$P(6 / m) m m \mathrm{t}\left(\overline{\left.2 / 3^{1 / 3}\right]^{1 / 2}}\right)$ \\
\end{tabular}} & \multirow{3}{*}{ 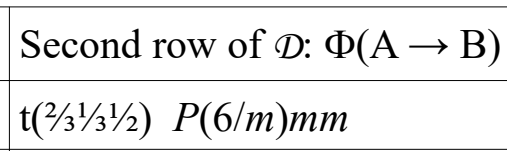 } \\
\hline & & & \\
\hline No. & Global operations & & \\
\hline 1 & $\left\{2_{001} \mid 000\right\}$ & $2 / 31 / 3 \overline{1} / 2$ & $2 / 31 / 31 / 2$ \\
\hline 2 & $\left\{6_{001}^{-} \mid 000\right\}$ & $\overline{1 / 3} 1 / 3^{1 / 2}$ & $2 / 31 / 31 / 2$ \\
\hline 3 & $\left\{6^{+}{ }_{001} \mid 000\right\}$ & $\overline{1 / 3 / 3 / 3 / 2}$ & $2 / 31 / 31 / 2$ \\
\hline 4 & $\left\{2_{110} \mid 000\right\}$ & $\overline{1 / 3 / 3 / 3} 1 / 2$ & $2 / 3 / 3 / 3 / 2$ \\
\hline 5 & $\left\{2_{100} \mid 000\right\}$ & $1 / 31 / 31 / 2$ & $2 / 31 / 31 / 2$ \\
\hline 6 & $\left\{2_{010} \mid 000\right\}$ & $2 / 31 / 31 / 2$ & $2 / 31 / 31 / 2$ \\
\hline 7 & $\{\overline{1} \mid 000\}$ & $2 / 31 / 31 / 2$ & $2 / 3^{1 / 3} 1 / 2$ \\
\hline 8 & $\left\{\overline{3}^{+}{ }_{001} \mid 000\right\}$ & $1 / 31 / 31 / 2$ & $2 / 31 / 31 / 2$ \\
\hline 9 & $\left\{\overline{3}_{001}^{-} \mid 000\right\}$ & $\overline{1 / 3 / 3} 1 / 2$ & $2 / 31 / 31 / 2$ \\
\hline 10 & $\left\{m_{1 \overline{1} 0} \mid 000\right\}$ & $1 / 3^{2 / 3} 1 / 2$ & $2 / 3^{1 / 3} 1 / 2$ \\
\hline 11 & $\left\{m_{120} \mid 000\right\}$ & $\overline{1 / 3} 1 / 3^{1 / 2}$ & $2 / 3 / 31 / 2$ \\
\hline 12 & $\left\{m_{210} \mid 000\right\}$ & $2 / 31 / 3^{1 / 2}$ & $2 / 31 / 31 / 2$ \\
\hline
\end{tabular}


Table 7. The partial operations of the groupoid of the AB polytype that are not prolonged to global operations. This occurs when the operations $\Phi(B \rightarrow$ A) and $\Phi(\mathrm{A} \rightarrow \mathrm{B})$ do not differ by a full lattice translation. The infinitely many operations of are represented by the 12 operations with a reduced translational component. The operations are represented by their Seitz symbol.

\begin{tabular}{|c|c|}
\hline$\Phi(\mathrm{B} \rightarrow \mathrm{A})$ & $\Phi(\mathrm{A} \rightarrow \mathrm{B})$ \\
\hline$P(6 / m) m m \mathrm{t}\left(\overline{2 / 3^{1 / 3} 3^{1 / 2}}\right)$ & $\mathrm{t}\left(2^{2} / 3^{1} / 3^{1} / 2\right) P(6 / m) m m$ \\
\hline$\left\{\mathrm{t} \mid \overline{2^{2 / 3} 1 / 31 / 2}\right\}$ & $\left\{\left.\mathrm{t}\right|^{2} / 31 / 31 / 2\right\}$ \\
\hline$\left\{3^{+}{ }_{001} \mid 1^{1 / 3} \overline{1 / 3} \frac{1}{1 / 2}\right\}$ & $\left\{\left.3^{+}{ }_{001}\right|^{2} / 3^{1 / 3} 3^{1} / 2\right\}$ \\
\hline$\left\{3_{001}^{-1 / 3^{2} / 3^{1 / 2}}\right\}$ & $\left\{\left.3_{001}^{-}\right|^{2} / 3^{1 / 3} 3^{1 / 2}\right\}$ \\
\hline$\left\{\left.2_{1 \overline{1} 0}\right|^{1 / 3} 3^{2} / 3^{1} / 2\right\}$ & $\left\{\left.2_{1 \overline{1}}\right|^{2 / 3} 3^{1} / 3 / 2\right\}$ \\
\hline$\left\{\left.2_{120}\right|^{1 / 3} \overline{1} 1 / 1 / 2\right\}$ & $\left\{\left.2_{120}\right|^{2 / 3} 3^{1 / 3} 1 / 2\right\}$ \\
\hline$\left\{\left.2_{210}\right|^{2 / 3 / 3 / 31 / 2}\right\}$ & $\left\{\left.2_{210}\right|^{2 / 3} 3^{1 / 3} 1 / 2\right\}$ \\
\hline$\left\{\left.m_{001}\right|^{2 / 3^{1} / 3^{1} / 2}\right\}$ & $\left\{\left.m_{001}\right|^{2} / 3^{1} / 3^{1} / 2\right\}$ \\
\hline$\left\{\left.\overline{6}_{001}\right|^{\left.1 / 33^{1 / 3} \overline{3}^{1 / 2}\right\}}\right.$ & $\left\{\left.\overline{6}_{001}^{-}\right|^{2 / 3} 3^{1 / 3}{ }^{1 / 2}\right\}$ \\
\hline$\left\{\left.\overline{6}^{+}{ }_{001}\right|^{1 / 3} 3^{2 / 3} 1 / 2\right\}$ & $\left\{\left.\overline{6}_{001}^{+}\right|^{2 / 3} 3^{1 / 3}{ }^{1 / 2}\right\}$ \\
\hline$\left\{\left.m_{110}\right|^{1 / 3} 3^{2 / 3} \overline{1} / 2\right\}$ & $\left\{\left.m_{110}\right|^{2 / 3} 3^{1 / 3} 3^{1 / 2}\right\}$ \\
\hline$\left\{\left.m_{100}\right|^{1 / 3} \overline{1 / 3} \frac{1}{3}\right\}$ & $\left\{\left.m_{100}\right|^{2} / 3^{1 / 3} 3^{1 / 2}\right\}$ \\
\hline$\left\{m_{010} \overline{\left.\right|^{2 / 3} 3^{1 / 3} / 2}\right\}$ & $\left\{\left.m_{010}\right|^{2} / 3^{1} / 3^{1} / 2\right\}$ \\
\hline
\end{tabular}



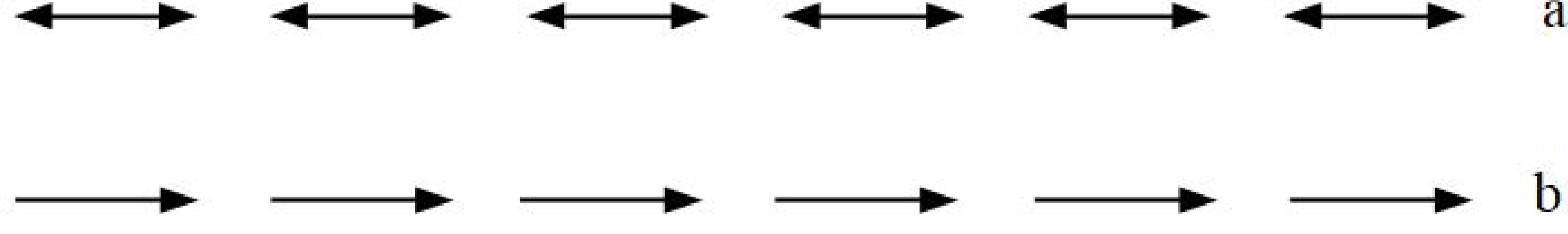

b

c

4
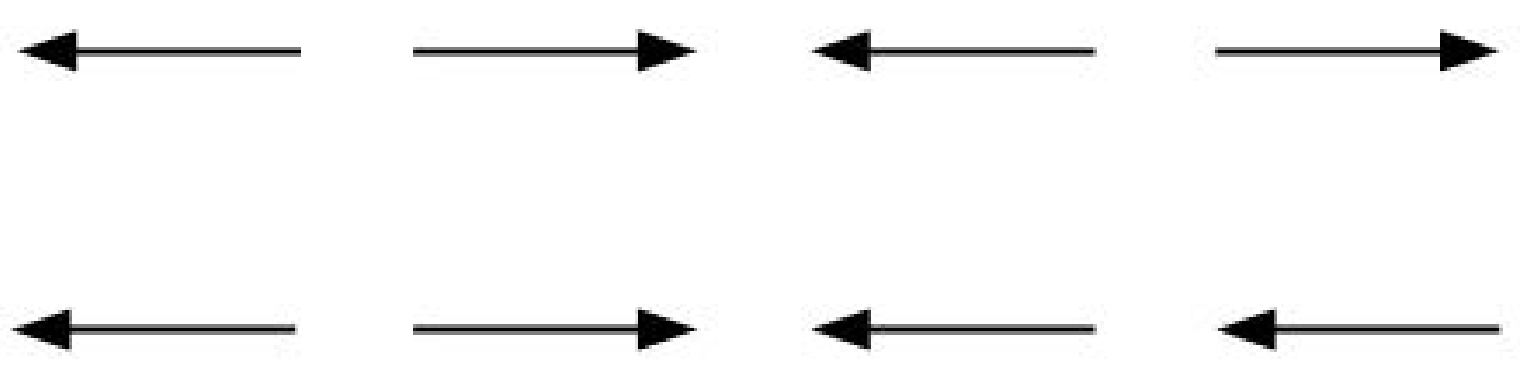

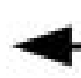
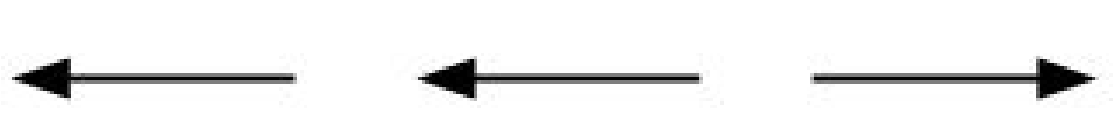

4

4

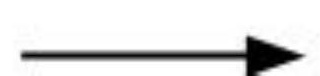

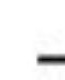



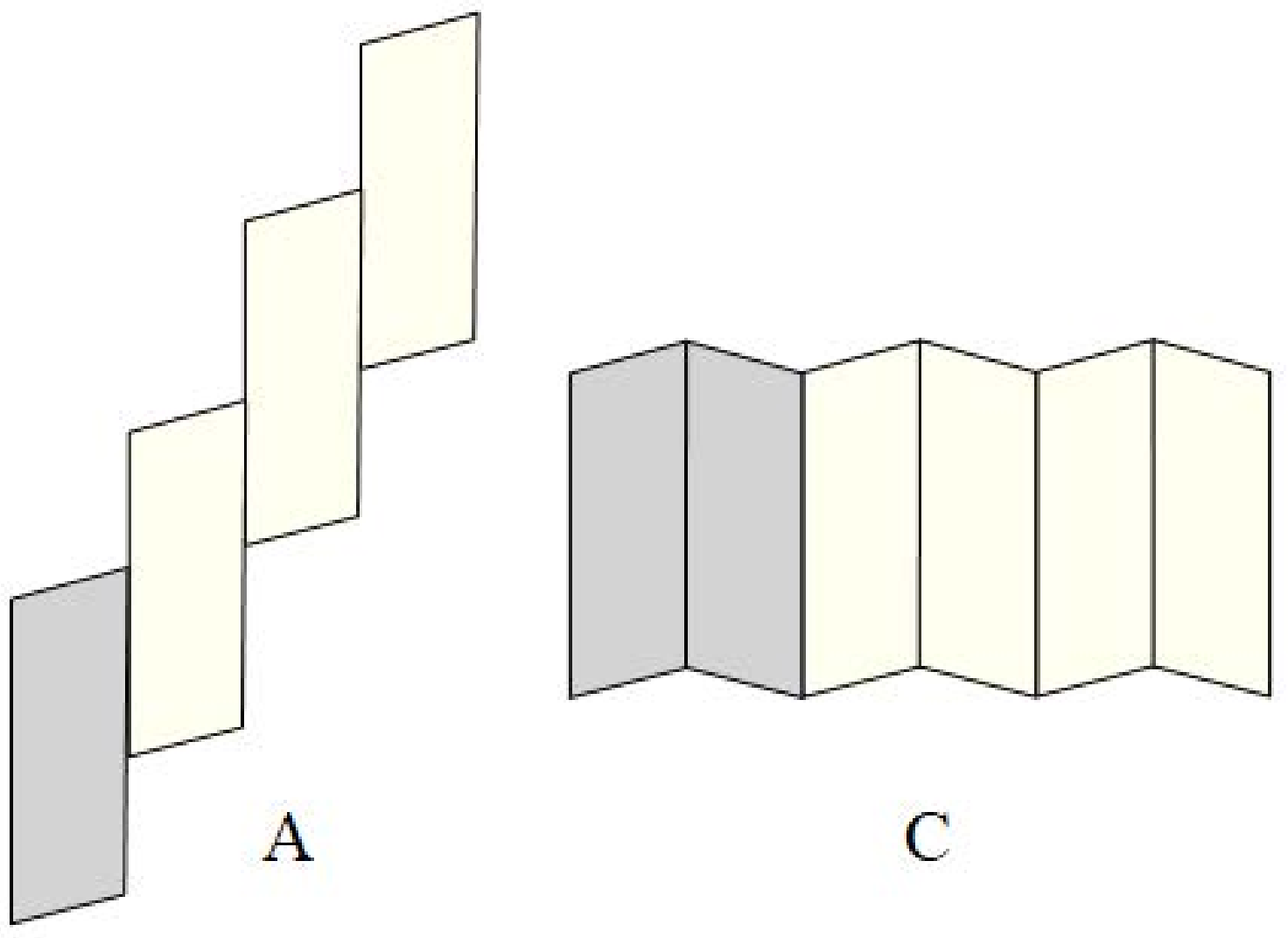

C 


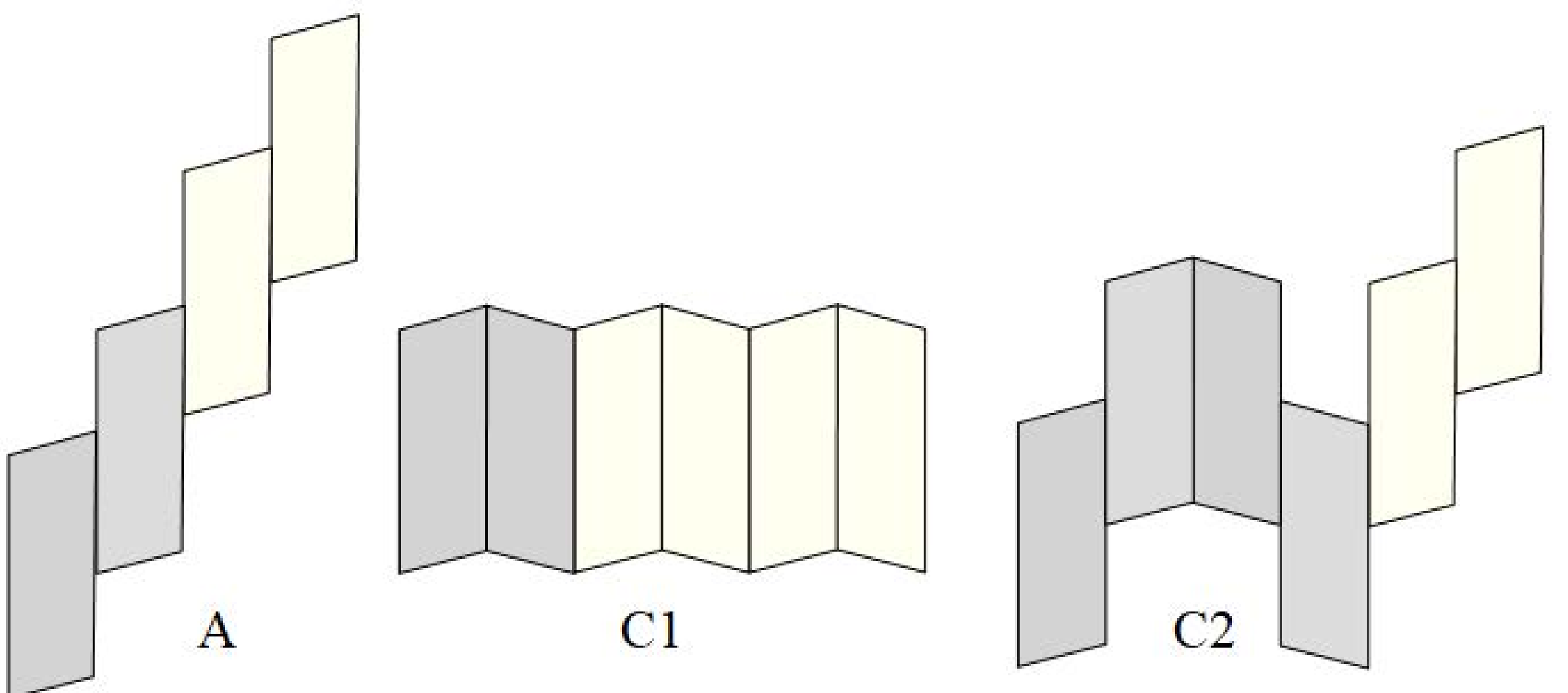



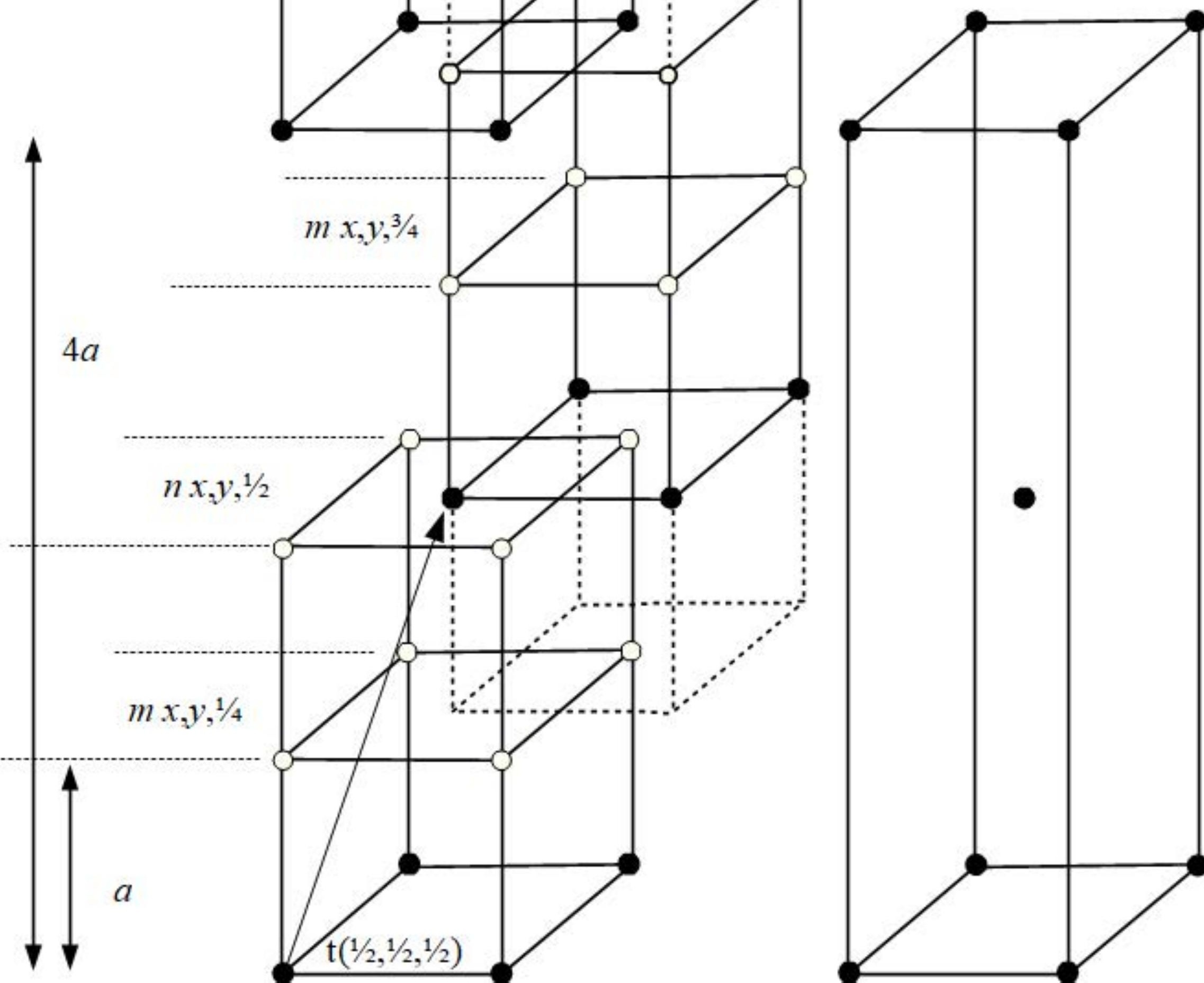


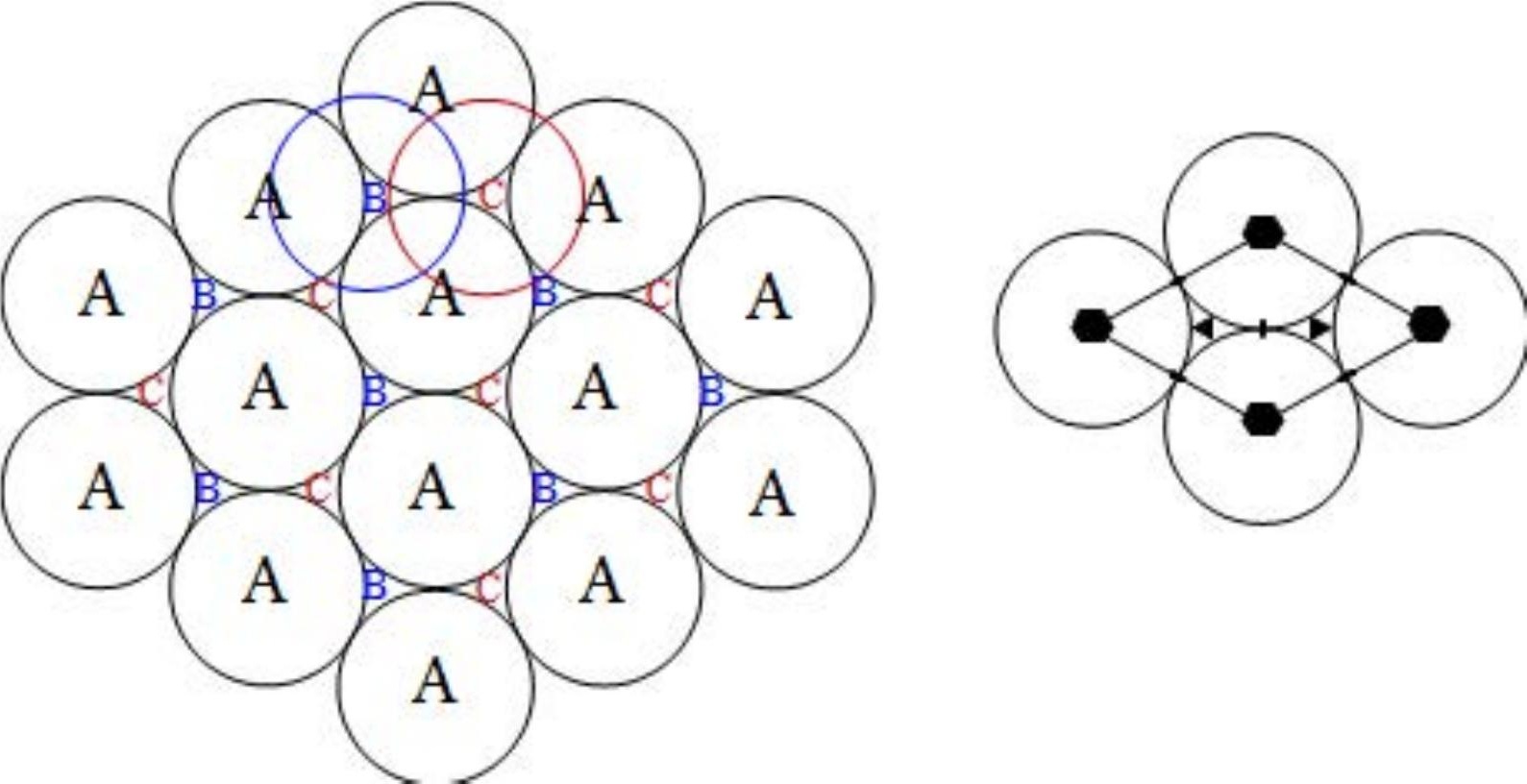




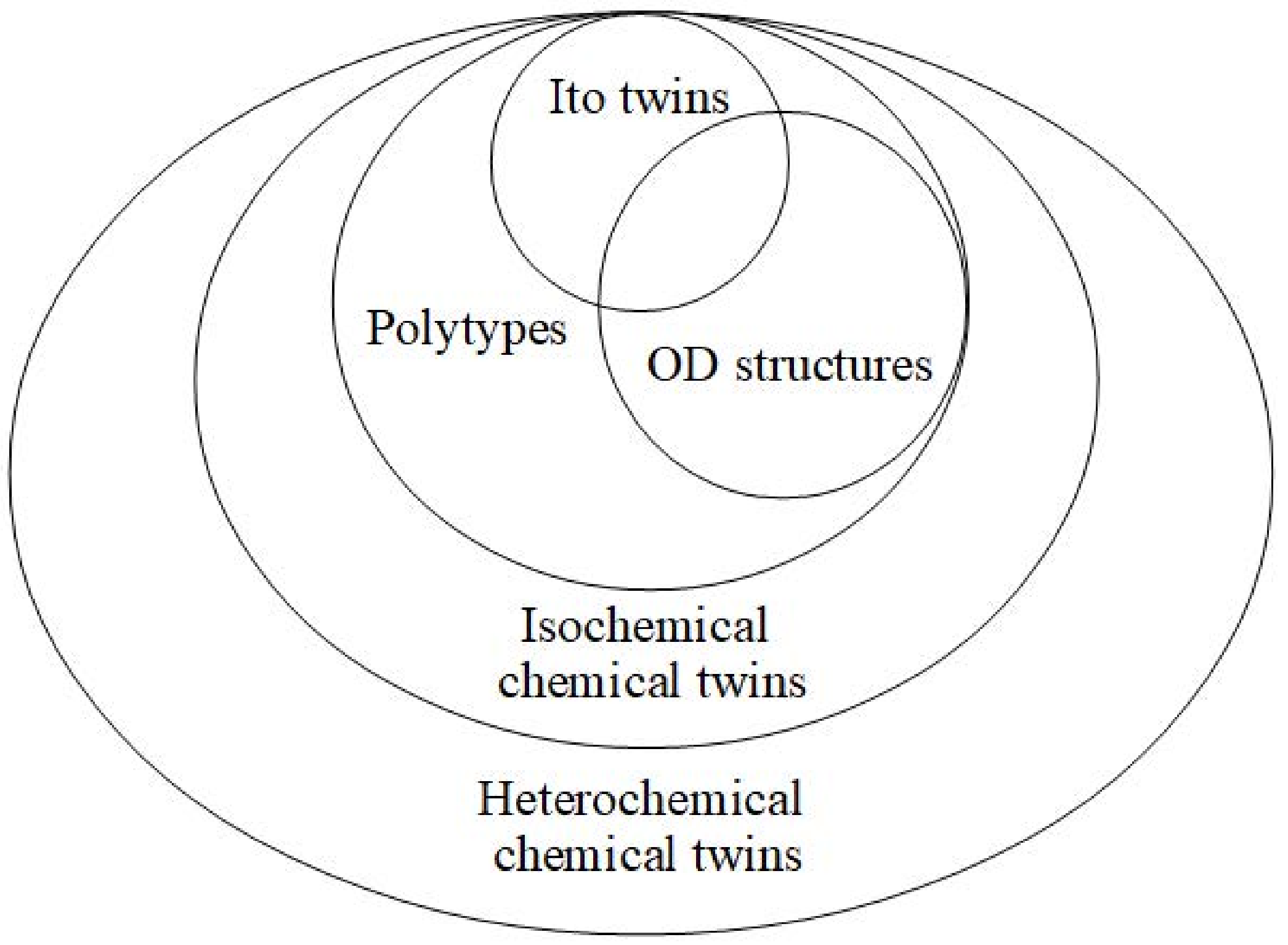

